\title{
Sulfur lodine Process Summary for the Hydrogen Technology Down-Selection
}

\author{
Benjamin Russ
}

May 2009

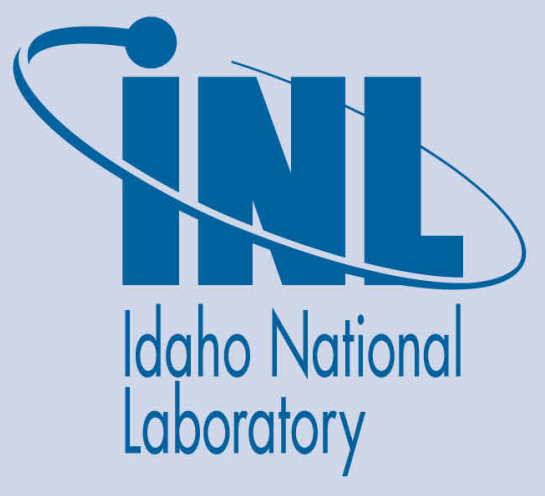

The INL is a U.S. Department of Energy National Laboratory operated by Battelle Energy Alliance 
INL/EXT-12-25773

\title{
Sulfur lodine Process Summary for the Hydrogen Technology Down-Selection
}

${ }^{1}$ General Atomics

\author{
Benjamin Russ ${ }^{1}$
}

May 2009

\author{
Idaho National Laboratory \\ Next Generation Nuclear Plant \\ Idaho Falls, Idaho 83415 \\ http://www.inl.gov \\ Prepared for the \\ U.S. Department of Energy \\ Office of Nuclear Energy \\ Under DOE Idaho Operations Office \\ Contract DE-AC07-05ID14517
}




\section{Table of contents}

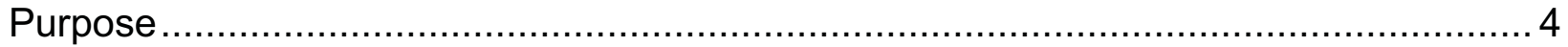

Sulfur lodine Baseline Process Summary .................................................................... 4

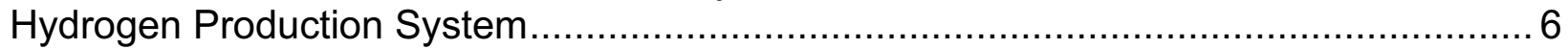

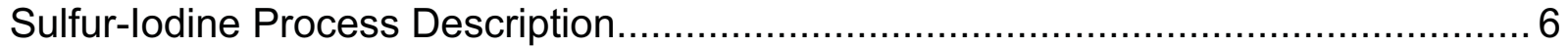

Section 1 (Bunsen Reaction) ........................................................................... 6

Section 2 (Sulfuric Acid Decomposition) ……............................................... 10

Section 3 (Hydrogen lodide Decomposition) ..................................................... 14

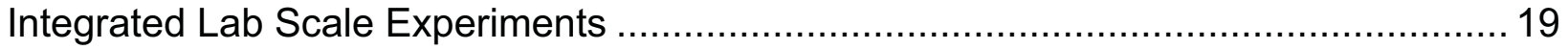

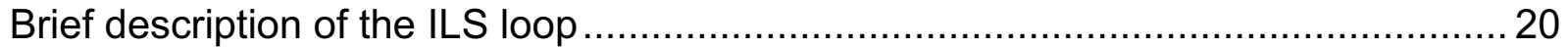

S-I Cycle Integrated Lab Scale Experiment Schedule ........................................ 20

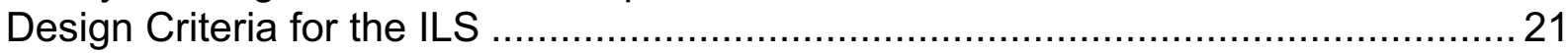

Bunsen Reaction Skid Description (Section 1) …........................................... 22

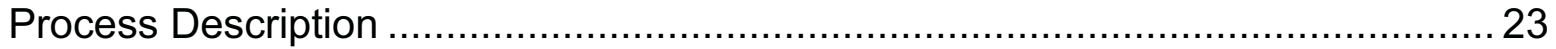

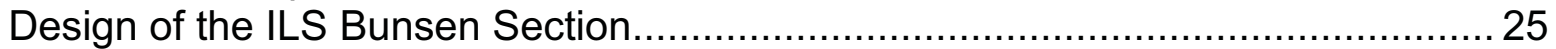

Sulfuric Acid Decomposition Skid Description (Section 2) .................................... 26

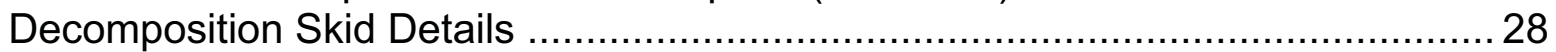

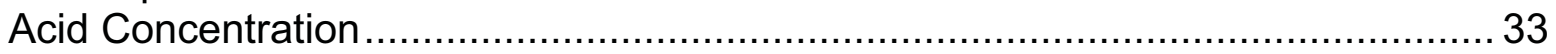

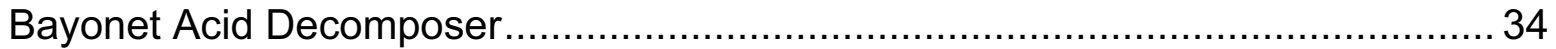

HI Decomposition Skid Description (Section 3) ……......................................... 34

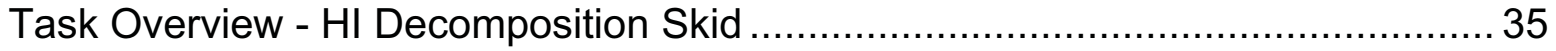

Design Criteria of the HI Decomposition Section .................................................. 36

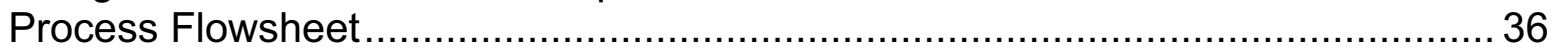

Interface Skid Description and Controls......................................................... 39

ILS Interfaces Between Section 1 and Section 2 ......................................... 40

ILS Interfaces Between Section 1 and Section 3 ............................................ 40

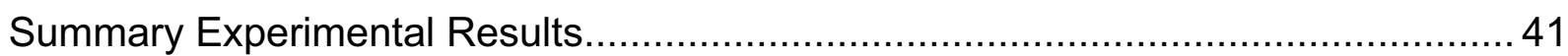

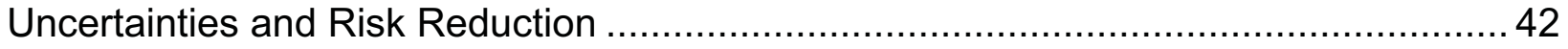

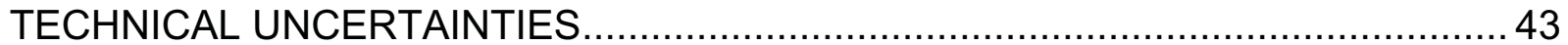

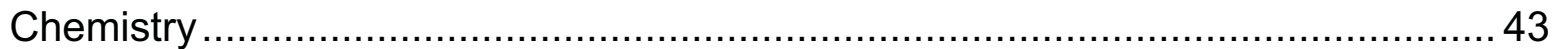

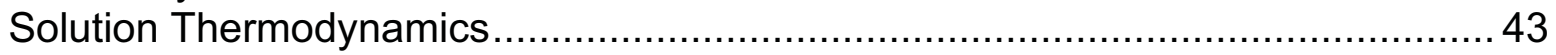

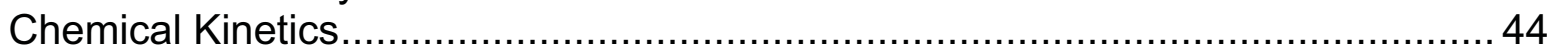

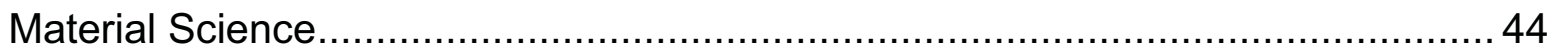

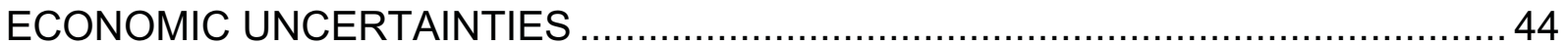

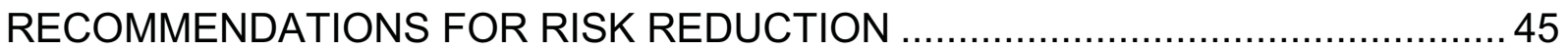

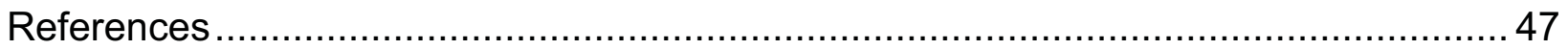

\section{List of Figures}

Figure 1 The SI Thermochemical Water Splitting Process ..................................... 5

Figure 2 Simplified SI Process Flow Schematic ................................................ 5

Figure 3 SI Process Section 1 Flow Stream Description ......................................... 8

Figure 4 SI Process Section 2 Flow Stream Description ........................................ 12

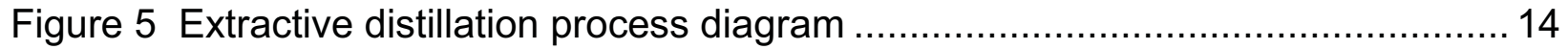

Figure 6 Reactive distillation process diagram ...................................................... 15 
Figure 7 SI Process Section 3 Flow Stream Description .......................................... 17

Figure $8 \mathrm{~A}$ schematic showing the four different skids of the ILS loop. ........................2 20

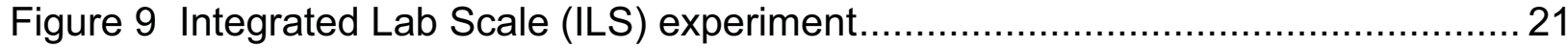

Figure 10 Bunsen section flowsheet......................................................... 22

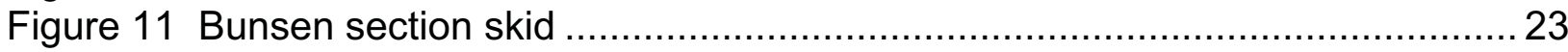

Figure 12 Bunsen Section. CEA proposed flow sheet...................................... 24

Figure 13 Sulfuric acid decomposition skid ................................................... 27

Figure14 Schematic layout of the $\mathrm{H}_{2} \mathrm{SO}_{4}$ decomposition section skid.......................2 29

Figure 15 The liquid acid side of the acid decomposition skid assembled at GA. ........31

Figure 16 The $\mathrm{SO}_{2}$ side of the acid decomposition skid assembled at GA................. 32

Figure17 Schematic of concentrator, excluding the surrounding electric heater. .........33

Figure 18 The SiC bayonet decomposer shown schematically on the left and the actual

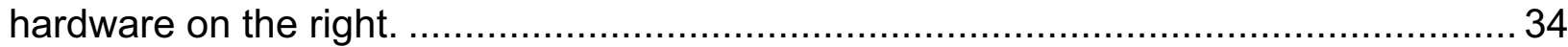

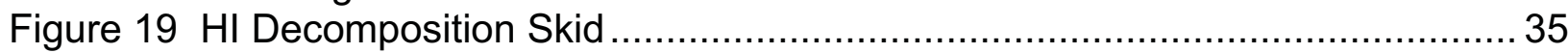

Figure 20 ILS Section 3 Flowsheet- Hydrogen lodide Decomposition ........................ 38

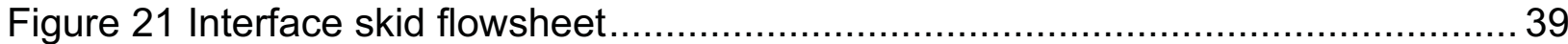

Figure 22 Interface Skid: $\mathrm{I}_{2} / \mathrm{HIx}$ tanks and Water $/ \mathrm{H}_{2} \mathrm{SO}_{4}$ tanks/Scrubber ................... 40

\section{List of Tables}

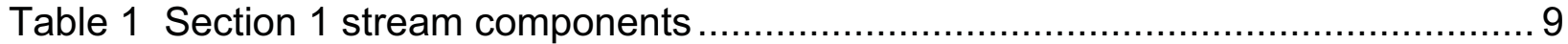

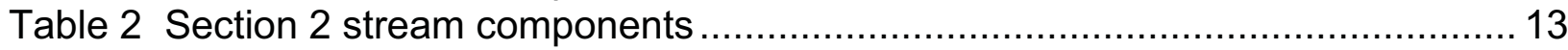

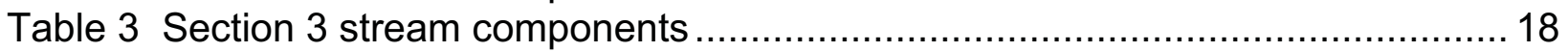

Table 4 Recommended Scaleup steps for SI process............................................. 46 


\section{Purpose}

This report summarizes the sulfur-iodine $(\mathrm{SI})$ thermochemical water splitting process for the purpose of supporting the process for evaluating and recommending a hydrogen production technology to deploy with the Next Generation Nuclear Plant (NGNP). This package provides the baseline process description as well as a comparison with the process as it was implemented in the Integrated Lab Scale (ILS) experiment conducted at General Atomics from 2006-2009.

\section{Sulfur lodine Baseline Process Summary}

As part of an earlier Nuclear Energy Research Initiative (NERI) study sponsored by the U.S. Department of Energy, a team headed by GA and supported by Sandia National Laboratories (SNL) and the University of Kentucky evaluated 115 different thermochemical cycles that produce hydrogen [Brown, 2003]. The sulfur-iodine (SI) cycle was determined to be the best cycle for coupling to a high temperature reactor (HTR) because of its high efficiency and potential for further improvement. The Japanese Atomic Energy Agency (JAEA) has also selected the SI process for further development and has successfully completed bench-scale demonstrations of the SI process at atmospheric pressure [Kubo, 2005]. JAEA also plans to proceed with pilotscale demonstrations of the SI process and eventually plans to couple an SI demonstration plant to its High Temperature Test Reactor (HTTR) [Terada, 2005], [lyoku, 2005]. As part of an international NERI project, GA, SNL, and the French Commissariat L'Energie Atomique performed laboratory-scale demonstrations of the SI process at prototypical temperatures and pressures. This demonstration was performed at General Atomics in San Diego, CA and concluded in April 2009.

Water thermally dissociates at significant rates into hydrogen and oxygen at temperatures approaching $4000^{\circ} \mathrm{C}$. As indicated in Figure 1, the SI process consists of three primary chemical reactions that accomplish this same result at much lower temperatures. The process involves decomposition of sulfuric acid and hydrogen iodide, and regeneration of these reagents using the Bunsen reaction. Process heat is supplied at temperatures equal to or greater than $700^{\circ} \mathrm{C}$ to concentrate and decompose sulfuric acid. The exothermic Bunsen reaction is performed at temperatures near $120^{\circ} \mathrm{C}$ and releases waste heat to the environment. Hydrogen is generated during the decomposition of hydrogen iodide, using process heat at temperatures greater than $300^{\circ} \mathrm{C}$. Figure 2 shows a simplified process flow diagram of the SI cycle. The product hydrogen gas is produced at a pressure of $4.0 \mathrm{MPa}$. 
Sulfuric acid is concentrated and decomposed at high temperatures

Excess water shifts chemical equilibrium by hydrating acids

Bunsen reaction produces acids and releases waste heat to the environment at low temperatures

Excess iodine shifts chemical equilibrium and separates acids by liquid-liquid phase equilibrium

Hydrogen iodide is concentrated and decomposed at moderate temperatures

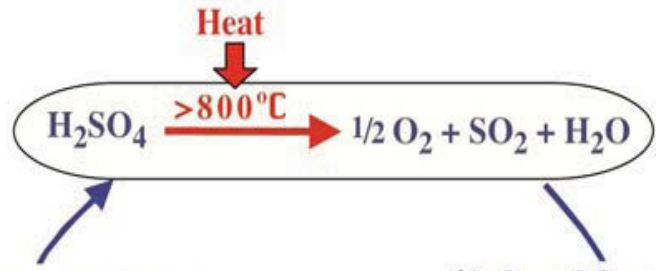

$$
\mathrm{H}_{2} \mathrm{SO}_{4}\left(\mathrm{H}_{2} \mathrm{O}\right) \quad 1 / 2 \mathrm{O}_{2}+\mathrm{SO}_{2}+\mathrm{H}_{2} \mathrm{O}
$$
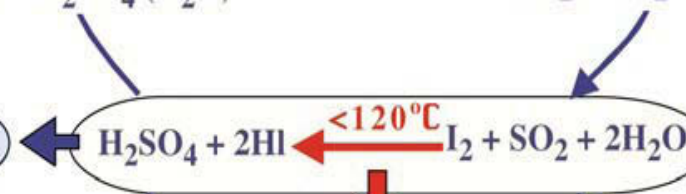

\section{Figure 1 The SI Thermochemical Water Splitting Process}

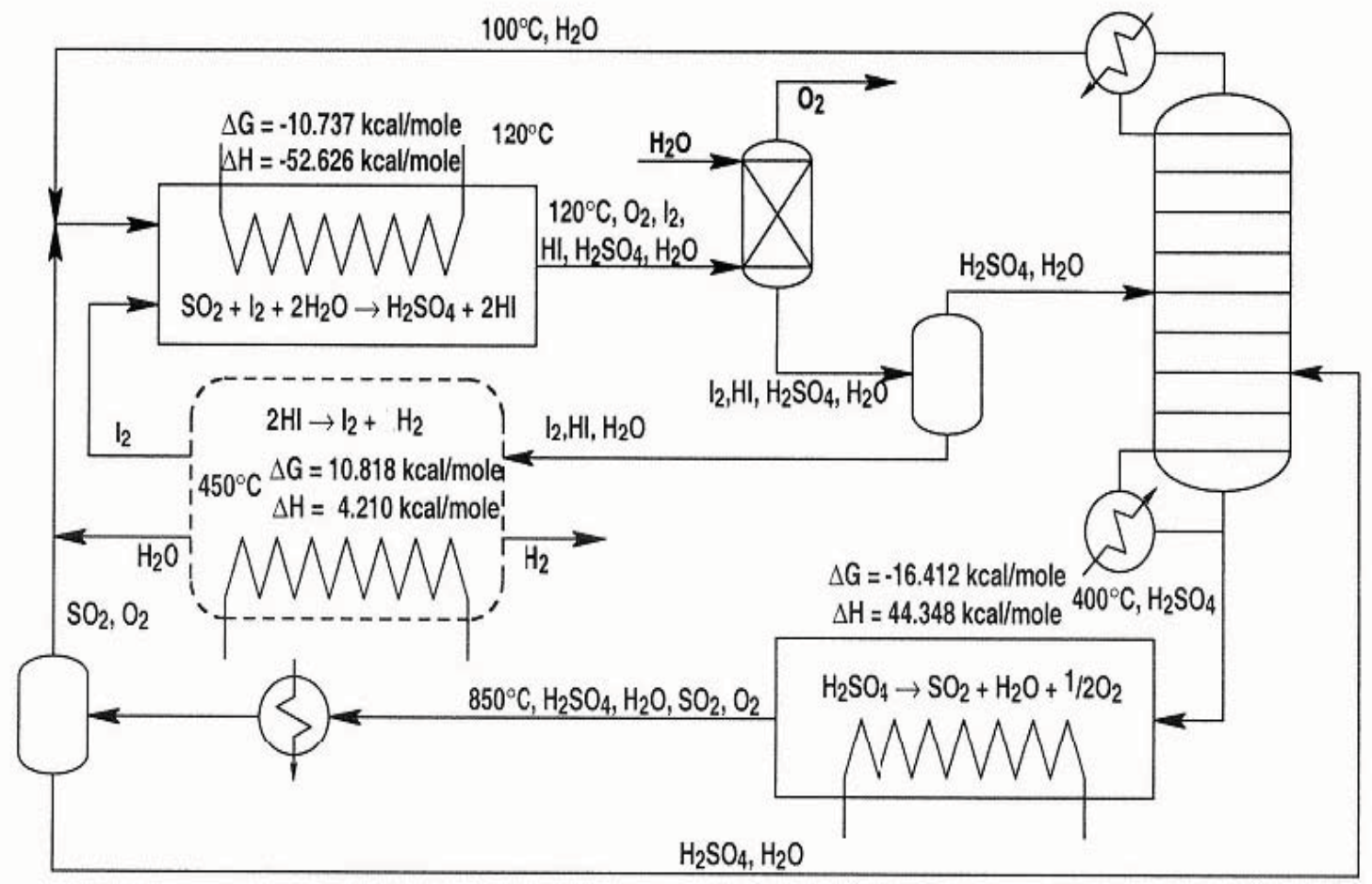

Figure 2 Simplified SI Process Flow Schematic 


\section{Hydrogen Production System}

The Hydrogen Production System design is based on the design described previously [Brown, 2003]. The current design reflects optimization of the flowsheets to increase the hydrogen production rate and to improve efficiency.

\section{Sulfur-lodine Process Description}

The S-I thermochemical cycle consists of three chemical reactions that result in dissociation of water into hydrogen at oxygen;

\begin{tabular}{lll} 
Bunsen Reaction: & $\mathrm{I}_{2}+\mathrm{SO}_{2}+2 \mathrm{H}_{2} \mathrm{O} \rightarrow 2 \mathrm{HI}+\mathrm{H}_{2} \mathrm{SO}_{4}$ & $\left(\mathrm{~T} \sim 120^{\circ} \mathrm{C}\right)$ \\
$\mathrm{H}_{2} \mathrm{SO}_{4}$ Decomposition: & $\mathrm{H}_{2} \mathrm{SO}_{4} \rightarrow \mathrm{SO}_{2}+\mathrm{H}_{2} \mathrm{O}+1 / 2 \mathrm{O}_{2}$ & $\left(\mathrm{~T}>800^{\circ} \mathrm{C}\right)$ \\
$\mathrm{HI}$ Decomposition: & $2 \mathrm{HI} \rightarrow \mathrm{I}_{2}+\mathrm{H}_{2}$ & $\left(\mathrm{~T}>350^{\circ} \mathrm{C}\right)$ \\
\hline Net & $\mathrm{H}_{2} \mathrm{O} \rightarrow \mathrm{H}_{2}+1 / 2 \mathrm{O}_{2}$ &
\end{tabular}

All three reactions are operated under conditions of chemical equilibrium. Energy inputs to the process are heat to the endothermic $\mathrm{H}_{2} \mathrm{SO}_{4}$ and $\mathrm{HI}$ decomposition reactions and electrical energy required for pumping process fluids and heat pumps. Heat at about $120^{\circ} \mathrm{C}$ is rejected from the exothermic Bunsen reaction. With the exception of water, all reactants are regenerated and recycled.

The Hydrogen Production System design is organized into subsystems according to these three chemical reactions. These subsystems are referred to as Sections 1, 2, and 3. Section 1 (Bunsen reaction) includes all the process equipment associated with production of the aqueous sulfuric acid phase and the hydrogen iodide $\left(\mathrm{HI} / \mathrm{I}_{2} / \mathrm{H}_{2} \mathrm{O}\right)$ phase. Section 1 also includes equipment to purify the oxygen before release. Section 2 concentrates the aqueous sulfuric acid phase and then decomposes the concentrated acid. The decomposition products and the water removed from concentrating the acid are returned to Section 1 . Section 3 concentrates and decomposes hydrogen iodide. Section 3 also includes equipment to purify the product hydrogen gas.

The flowsheets for Sections 2 and 3 have been analyzed and optimized using AspenPlus process-simulation software. Because the thermodynamic data for the thermophysical properties are still limited for the $\mathrm{HI} / \mathrm{I}_{2} / \mathrm{H}_{2} \mathrm{O}$ vapor equilibrium, the equilibrium conditions for Section 1 are based on previous calculations [Norman, 1982] Approximately two-thirds of the fresh water required for hydrogen production is supplied to Section 3 and the remainder is supplied to Section 1 . The product hydrogen gas is produced at a pressure of $4.0 \mathrm{MPa}$.

\section{Section 1 (Bunsen Reaction)}

The flowsheet for Section 1 is shown in Figure 3 and the stream compositions are shown in Table 1. This flowsheet is essentially the same as that described previously 
[Brown, 2003] and is based on experimental data obtained in the 1980s and later validated during the Integrated Lab Scale experiment during 2006-2009. A key component in Section 1 is the flow reactor R101, which functions as a heat exchanger. Because the kinetics of the Bunsen reaction are very fast, the rate of heat transfer controls the reaction rate. The mixture exiting R101 consists of three immiscible phases, of which two are liquid and one is gas. These phases are separated in component $\mathrm{S} 101$. The lower phase, which consists of $\mathrm{HI} / \mathrm{I}_{2} / \mathrm{H}_{2} \mathrm{O}$ in the approximate molar ratios 2/8/10, is stripped of dissolved $\mathrm{SO}_{2}$ and $\mathrm{H}_{2} \mathrm{SO}_{4}$ in the packed column $\mathrm{C} 102$. Prior to stripping, the pressure is lowered in order to use a recycle $\mathrm{O}_{2}$ stream as the stripping agent. The $\mathrm{SO}_{2}$ is directly stripped by the $\mathrm{O}_{2}$ stream. As the $\mathrm{SO}_{2}$ is depleted, the reaction equilibrium shifts to produce more $\mathrm{SO}_{2}$ from $\mathrm{H}_{2} \mathrm{SO}_{4}$ reacting with $\mathrm{HI}$, which results in simultaneous removal of $\mathrm{SO}_{2}$ and $\mathrm{H}_{2} \mathrm{SO}_{4}$. The stripped lower phase exits C102 and is transferred to Section 3 , where it is processed to produce the hydrogen product gas. The upper phase exiting $\mathrm{S} 101$ (aqueous $\mathrm{H}_{2} \mathrm{SO}_{4}$ ) is transferred to boost reactor $\mathrm{C} 103$, which is a packed column. A portion of the upper phase exiting $\mathrm{C} 102\left(\mathrm{O}_{2}\right.$ and $\mathrm{SO}_{2}$ ) is also transferred to $\mathrm{C} 103$. In this column, the sulfuric acid is concentrated by contacting it with $\mathrm{I}_{2}$ and $\mathrm{SO}_{2}$. The molar ratio of $\mathrm{H}_{2} \mathrm{SO}_{4}$ to $\mathrm{H}_{2} \mathrm{O}$ entering $\mathrm{C} 103$ is about 1:6 and is increased to about 1:4 at the exit of C103.

The remaining equipment in Section 1 is associated with processing the $\mathrm{O}_{2}$ stream. The $\mathrm{SO}_{2}$ is scrubbed from the $\mathrm{O}_{2}$ stream in packed column C101. A small amount of iodine is added to $\mathrm{C} 101$ in order to minimize the amount of water required to remove $\mathrm{SO}_{2}$ via the Bunsen reaction. The water streams to C101 are supplied from Section 2 and are cooled prior to entering $\mathrm{C} 101$ in order to remove the heat of reaction and minimize the amount of heat that is removed by $\mathrm{R} 103$. The $\mathrm{SO}_{2}$ remaining in the upper phase that exits boost reactor $\mathrm{C} 103$ is scrubbed from the oxygen in packed column $\mathrm{C} 104$. Because all of the SO2 exiting C102 cannot be used in boost reactor $\mathrm{C} 103$, a portion of this stream is transferred to packed column $\mathrm{C} 105$ to scrub the $\mathrm{SO}_{2}$ from the oxygen. This $\mathrm{SO}_{2}$ is then transferred to R101. Energy recovery turbines are used to recover the work available from the compressed gasses and to provide the $\mathrm{O}_{2}$ stripping gas at an appropriate pressure.

Because the design point at the outlet of component R101 is essentially fixed in terms of temperature, compositions of both liquid phases, and the partial pressure of $\mathrm{SO} 2$, the only free variable is the system pressure. The system pressure must be below the operating pressure of Section 2 so that the gases can flow from Section 2 without compression. The pressure must also be sufficiently high for efficient operation of the $\mathrm{SO}_{2}$ stripping column. Operating R101 at higher pressures does provide the benefit of a lower $\mathrm{SO}_{2}$ to $\mathrm{O}_{2}$ ratio at the exit of this reactor, which leaves less $\mathrm{SO}_{2}$ to be removed in the first oxygen scrubber (C101). The operating pressure for R101 has been set at $0.7 \mathrm{MPa}$. 


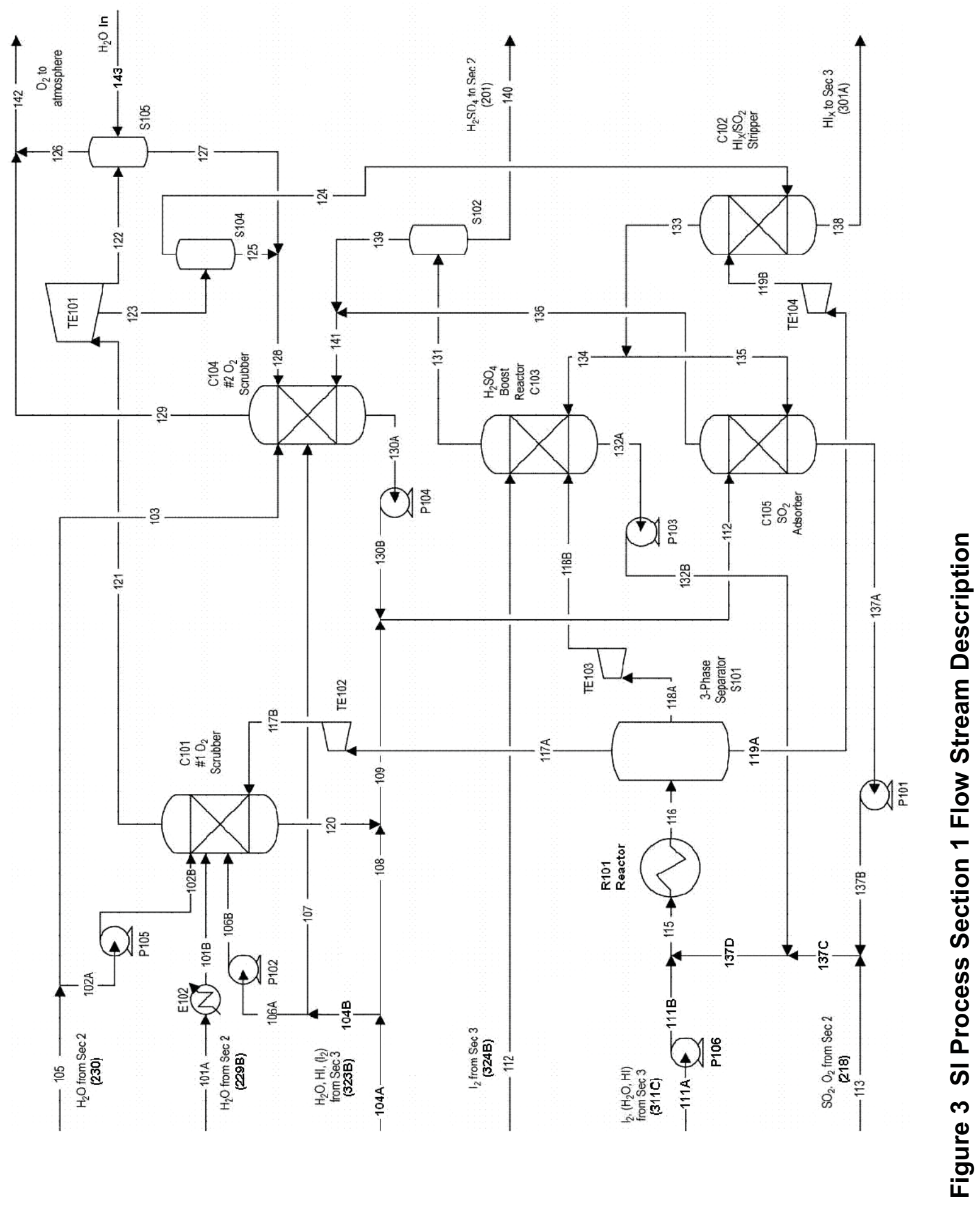


Table 1 Section 1 stream components

\begin{tabular}{|c|c|c|c|c|c|c|c|c|c|}
\hline \multirow[t]{2}{*}{$\begin{array}{l}\text { Stream } \\
\text { ID } \\
\end{array}$} & \multicolumn{6}{|c|}{ Species Present } & \multirow[b]{2}{*}{ Phase } & \multirow[b]{2}{*}{$\begin{array}{c}\text { Pressure } \\
\text { (Bar) }\end{array}$} & \multirow[b]{2}{*}{$\begin{array}{l}\text { Temp. } \\
\left({ }^{\circ} \mathrm{C}\right)\end{array}$} \\
\hline & $\mathrm{H}_{2} \mathrm{SO}_{4}$ & $\mathrm{HI}$ & $\mathbf{I}_{2}$ & $\mathrm{H}_{2} \mathrm{O}$ & $\mathrm{SO}_{2}$ & $\mathrm{O}_{2}$ & & & \\
\hline $101 \mathrm{~A}$ & $x$ & & & $X$ & $x$ & & $\mathrm{~L}$ & 12.00 & 40.6 \\
\hline 101B & $x$ & & & $X$ & $x$ & & $\mathrm{~L}$ & 12.00 & 86.5 \\
\hline $102 \mathrm{~A}$ & $x$ & & & $\mathrm{X}$ & $\mathrm{X}$ & $X$ & $\mathrm{~L}$ & 1.01 & 38.0 \\
\hline $102 \mathrm{~B}$ & $x$ & & & $\mathrm{X}$ & $\mathrm{X}$ & $x$ & $\mathrm{~L}$ & 4.40 & 38.0 \\
\hline 103 & $\mathrm{X}$ & & & $\mathrm{X}$ & & & $\mathrm{L}$ & 1.01 & 38.0 \\
\hline $104 \mathrm{~A}$ & & $x$ & $x$ & $x$ & & & $\mathrm{~L}$ & 7.00 & 120.4 \\
\hline 104B & & $x$ & $x$ & $x$ & & & L & 7.00 & 120.4 \\
\hline 105 & $\mathrm{X}$ & & & $\mathrm{X}$ & $\mathrm{X}$ & $x$ & $\mathrm{~L}$ & $\mathrm{~L}$ & -272.1 \\
\hline $106 \mathrm{~A}$ & & $\mathrm{X}$ & $x$ & $x$ & & & $L$ & 7.00 & 120.4 \\
\hline $106 \mathrm{~B}$ & & $x$ & $x$ & $x$ & & & $\mathrm{~L}$ & 12.00 & 120.4 \\
\hline 107 & & $x$ & $x$ & $\mathrm{X}$ & & & $\mathrm{L}$ & 1.01 & 95.4 \\
\hline 108 & & & $x$ & $x$ & & & L & 4.20 & 95.4 \\
\hline 109 & $\mathrm{X}$ & $x$ & $x$ & $x$ & $X$ & $x$ & $L$ & 1.85 & 119.9 \\
\hline $111 \mathrm{~A}$ & & $X$ & $x$ & $X$ & & & L & 7.00 & 118.8 \\
\hline 111B & & $X$ & $x$ & $x$ & & & $\mathrm{~L}$ & 12.00 & 119.9 \\
\hline 112 & & $X$ & $x$ & $X$ & & & $L$ & 7.00 & 115.6 \\
\hline 113 & & & & $x$ & $X$ & $x$ & $\mathrm{~V}$ & 7.00 & 40.1 \\
\hline 115 & $x$ & $x$ & $x$ & $X$ & $X$ & $X$ & $V+L$ & 7.00 & 115.6 \\
\hline 116 & $X$ & $X$ & $x$ & $x$ & $X$ & $x$ & $V+\mathrm{L}$ & 7.00 & 119.9 \\
\hline $117 \mathrm{~A}$ & & & $x$ & $x$ & $X$ & $x$ & $\mathrm{~V}$ & 7.00 & 119.9 \\
\hline 117B & & & $x$ & $X$ & $X$ & $x$ & $\mathrm{~V}$ & 4.20 & 81.1 \\
\hline $118 \mathrm{~A}$ & $X$ & & & $x$ & $X$ & & L & 7.00 & 119.9 \\
\hline 118B & $X$ & & & $x$ & $X$ & & $L$ & 1.85 & 119.9 \\
\hline $119 \mathrm{~A}$ & & $X$ & $x$ & $X$ & $X$ & & $\mathrm{~L}$ & 7.00 & 119.9 \\
\hline 119B & & $X$ & $x$ & $x$ & $x$ & & $\mathrm{~L}$ & 1.85 & 119.9 \\
\hline 120 & $X$ & $X$ & $x$ & $X$ & $X$ & $X$ & L & 4.20 & 111.3 \\
\hline 121 & & & & $X$ & & $X$ & $\mathrm{~V}$ & 4.20 & 111.3 \\
\hline 122 & & & & $x$ & & $x$ & $L+V$ & 1.01 & 111.3 \\
\hline 123 & & & & $X$ & & $X$ & $L+V$ & 1.85 & 15.9 \\
\hline 124 & & & & $x$ & & $x$ & $\mathrm{~V}$ & 1.85 & 15.9 \\
\hline 125 & & & & $x$ & & & $L$ & 1.85 & 15.9 \\
\hline 126 & & & & $X$ & & $x$ & V & 1.01 & 15.9 \\
\hline 127 & & & & $x$ & & & $L$ & 1.01 & 15.9 \\
\hline 128 & & & & $X$ & & & $L$ & 1.01 & 15.9 \\
\hline 129 & & & & $x$ & & $x$ & V & 1.01 & 39.9 \\
\hline $130 \mathrm{~A}$ & $X$ & $X$ & $X$ & $x$ & & & $L$ & 1.01 & 119.9 \\
\hline $130 \mathrm{~B}$ & $x$ & $x$ & $x$ & $X$ & & & $L$ & 1.85 & 119.9 \\
\hline 131 & $X$ & & $x$ & $x$ & $X$ & $x$ & $\mathrm{~L}$ & 1.85 & 111.4 \\
\hline $132 \mathrm{~A}$ & & $X$ & $x$ & $X$ & $X$ & & $L$ & 1.85 & 111.4 \\
\hline $132 \mathrm{~B}$ & & $x$ & $x$ & $x$ & $x$ & & $\mathrm{~L}$ & 7.00 & 111.4 \\
\hline 133 & & & $x$ & $X$ & $X$ & $X$ & V & 1.85 & 119.9 \\
\hline 134 & & & $X$ & $x$ & $x$ & $X$ & $\mathrm{~V}$ & 1.85 & 119.9 \\
\hline 135 & & & $x$ & $x$ & $x$ & $x$ & $\mathrm{~V}$ & 1.85 & 119.9 \\
\hline
\end{tabular}




\begin{tabular}{|c|c|c|c|c|c|c|c|c|c|}
136 & & & $\mathrm{X}$ & $\mathrm{X}$ & $\mathrm{X}$ & $\mathrm{X}$ & $\mathrm{V}$ & 1.85 & 96.5 \\
\hline $137 \mathrm{~A}$ & $\mathrm{X}$ & $\mathrm{X}$ & $\mathrm{X}$ & $\mathrm{X}$ & $\mathrm{X}$ & & $\mathrm{L}$ & 1.85 & 96.5 \\
\hline $137 \mathrm{~B}$ & $\mathrm{X}$ & $\mathrm{X}$ & $\mathrm{X}$ & $\mathrm{X}$ & $\mathrm{X}$ & & $\mathrm{L}$ & 7.00 & 96.5 \\
\hline $137 \mathrm{C}$ & & $\mathrm{X}$ & $\mathrm{X}$ & $\mathrm{X}$ & & & $\mathrm{L}$ & 1.85 & 119.9 \\
\hline $137 \mathrm{D}$ & & & $\mathrm{X}$ & $\mathrm{X}$ & $\mathrm{X}$ & $\mathrm{X}$ & $\mathrm{V}$ & 1.85 & 111.4 \\
\hline 140 & $\mathrm{X}$ & & & $\mathrm{X}$ & $\mathrm{X}$ & & $\mathrm{L}$ & 1.85 & 111.4 \\
\hline 141 & & & $\mathrm{X}$ & $\mathrm{X}$ & $\mathrm{X}$ & $\mathrm{X}$ & $\mathrm{V}$ & 1.85 & 102.0 \\
\hline 142 & & & & $\mathrm{X}$ & & $\mathrm{X}$ & $\mathrm{V}$ & 1.01 & 24.9 \\
\hline 143 & & & & $\mathrm{X}$ & & & $\mathrm{L}$ & 1.01 & 24.9 \\
\hline
\end{tabular}

\section{Section 2 (Sulfuric Acid Decomposition)}

The flowsheet for Section 2 is shown in Figure 4 and the stream compositions are shown in Table 2. Section 2 concentrates and decomposes the aqueous sulfuric acid phase that is transferred from Section 1. All of the heat from the secondary Helium Loop System (HLS) from the reactor is transferred to Section 2. As previously discussed, the sulfuric acid vaporizers and decomposers are operated at a pressure slightly lower than that of the secondary helium coolant in order to prevent chemical contamination of the Secondary HLS while minimizing pressure differentials across these components.

The $\mathrm{H}_{2} \mathrm{SO}_{4} / \mathrm{H}_{2} \mathrm{O}$ stream from Section 1 (201) is concentrated in three successive vacuum flashes. The first flash (S201) is adiabatic but heat is added in the other two flashes. The first flash cools the stream significantly below the temperatures of Section 1 so that heat released in R103 can be used to evaporate water in the second flash (S202) of Section 2. The third vacuum flash (S203) uses heat recovered from Section 3 . The vapors from the three flashes are cooled and the condensate returned to Section 1 (229B), as are the condensed vapors from the vacuum pump (228B). The concentrated acid is pumped from vacuum conditions to the pressure of the decomposition subsection using P201 and passed to the counter-current vapor-liquid recuperator $(\mathrm{H} 206)$.

The hot liquid from the recuperator is heated and vaporized in three stages. The first two evaporators ( $\mathrm{H} 207$ and $\mathrm{H} 208 \mathrm{~A})$ are flow-through evaporators, with the stream progressively vaporized as it passes through the counter current heat exchangers. The condensate from the decomposer product is added between the first and second vaporizers. Any minerals that enter with the deionized water feed to the process and any mobile corrosion products from the entire system will eventually be deposited in the sulfuric acid decomposition process. If the final evaporation occurred while the stream was flowing through tubes, the minerals and corrosion products could deposit on the heat transfer surfaces and contribute to fouling or even plugging. For this reason, the third vaporizer (H208B) is a pool-type unit.

The sulfuric acid vapors are decomposed in two steps; 


$$
\begin{array}{ll}
\mathrm{H}_{2} \mathrm{SO}_{4} \leftrightarrow \mathrm{SO}_{3}+\mathrm{H}_{2} \mathrm{O} & \left(\mathrm{T}>450^{\circ} \mathrm{C}\right) \\
\mathrm{SO}_{3} \rightarrow \mathrm{SO}_{2}+1 / 2 \mathrm{O}_{2} & \left(\mathrm{~T}>800^{\circ} \mathrm{C}\right)
\end{array}
$$

The first reaction is very fast and equilibrium is maintained, shifting to more complete decomposition as the temperature is raised or as $\mathrm{SO}_{3}$ is removed by the second reaction. The first reaction begins to occur in the final vaporizer (H208B), but most of the vaporization occurs primarily in $\mathrm{H} 209$, which is a standard counter-current heat exchanger.

The second reaction requires a catalyst. The catalytic reaction occurs in two decomposers (H210A and H210B). Conceptually the decomposers are counter-current heat exchangers with catalyst on the heat transfer surfaces. The differences between the two decomposers are in how they are heated. H210B is heated with helium from the Secondary HTS (HE1). Decomposer H210A, which operates at slightly lower temperatures, is heated with both secondary helium (HE2) and the decomposer product (213A). In addition, both helium and decomposer product are used in parallel to heat the gas-gas recuperator $(\mathrm{H} 209)$ and vaporizers 2 and 3 (H208A and H208B). Only the decomposer product is used to heat the first vaporizer $(\mathrm{H} 207)$. Finally, the decomposer is used to provide the heat requirements for Section $3(\mathrm{H} 213 \mathrm{~A})$. Some condensation occurs in this final heat exchanger. The product gases (215A) are separated (S207) from the condensate and pass to the gas-liquid recuperator $(\mathrm{H} 206)$. The condensate (214) is recycled to the second vaporizer $(\mathrm{H} 208 \mathrm{~A})$. The condenser $(\mathrm{H} 213 \mathrm{~A})$ and separator (S207) are physically located above the vaporizers (H208A and H208B) such that the gravitational head exceeds the pressure drop through the decomposition system, which eliminates the need for a pump capable of operating at these extreme conditions.

The two-phase product from the decomposition system (215B) is separated and power is recovered separately from the two phases. Each phase is cooled to as low a temperature as practical before they are transferred to Section 1. Condensate from the cooling process is transferred separately to Section 1. 


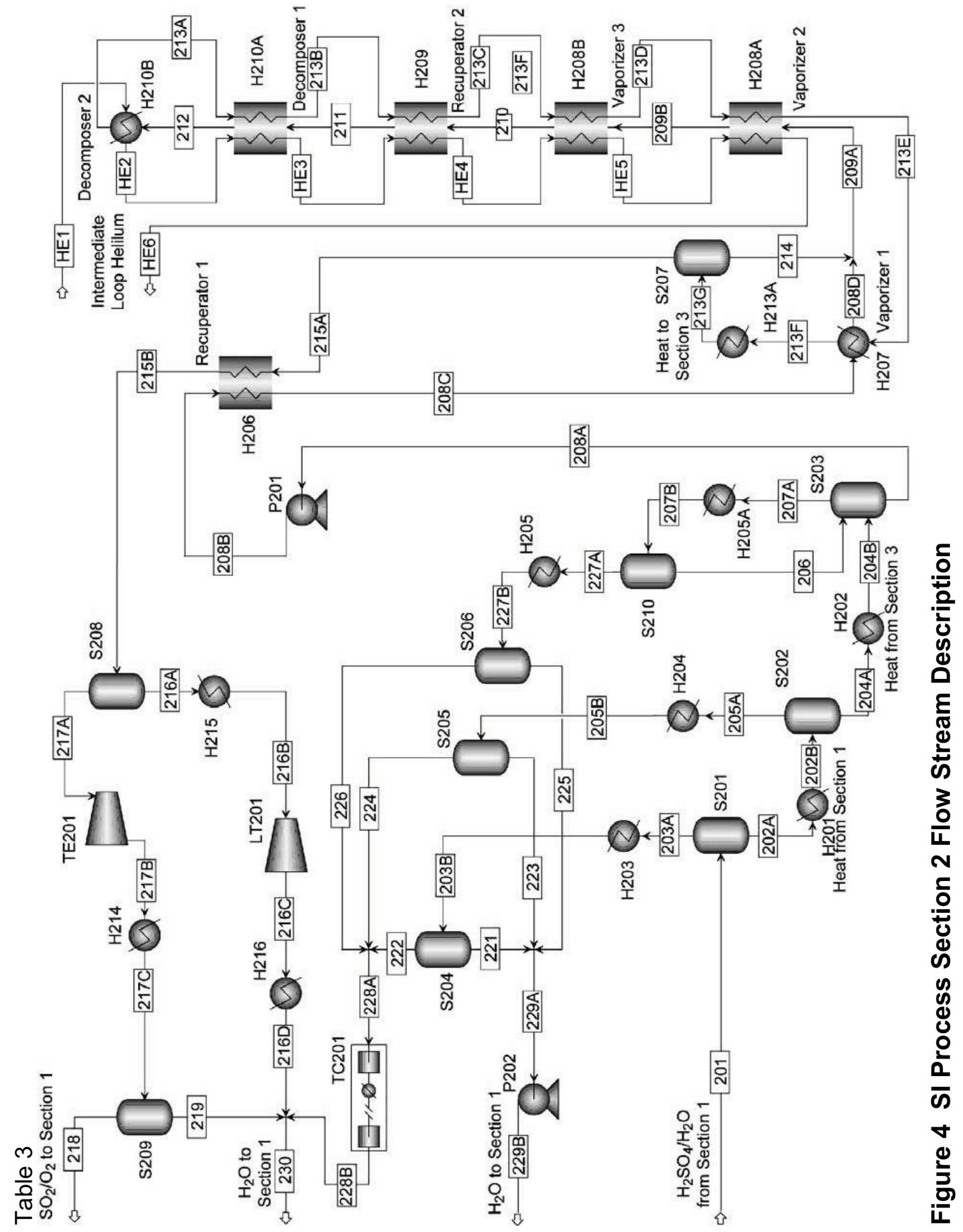


Table 2 Section 2 stream components

\begin{tabular}{|c|c|c|c|c|c|c|c|c|c|}
\hline \multirow[t]{2}{*}{$\begin{array}{l}\text { Stream } \\
\text { ID }\end{array}$} & \multicolumn{6}{|c|}{ Species Present } & \multirow[b]{2}{*}{ Phase } & \multirow[b]{2}{*}{$\begin{array}{c}\text { Pressure } \\
\text { (Bar) }\end{array}$} & \multirow[b]{2}{*}{$\begin{array}{c}\text { Temp } \\
\left({ }^{\circ} \mathrm{C}\right)\end{array}$} \\
\hline & $\mathrm{H}_{2} \mathrm{SO}_{4}$ & HI & $\mathrm{I}_{2}$ & $\mathrm{H}_{2} \mathrm{O}$ & $\mathrm{SO}_{2}$ & $\mathrm{O}_{2}$ & & & \\
\hline 201 & $x$ & $x$ & & $x$ & & $\mathrm{X}$ & $\mathrm{L}$ & 1.85 & 111.8 \\
\hline $202 A$ & $X$ & $x$ & & $\mathrm{X}$ & & $X$ & $\mathrm{~L}$ & 0.1 & 66.4 \\
\hline 202B & $X$ & $\mathrm{X}$ & & $x$ & & $X$ & $V+L$ & 0.1 & 110 \\
\hline $203 \mathrm{~A}$ & $\mathrm{X}$ & & & $\mathrm{X}$ & & $\mathrm{X}$ & $\mathrm{V}$ & 0.1 & 66.4 \\
\hline $203 B$ & $x$ & & & $x$ & & $\mathrm{X}$ & $\mathrm{V}$ & 0.1 & 40 \\
\hline $204 \mathrm{~A}$ & $\mathrm{X}$ & $\mathrm{X}$ & & & & $\mathrm{X}$ & $\mathrm{L}$ & 0.1 & 110 \\
\hline 204B & $\mathrm{X}$ & $\mathrm{X}$ & & & & $X$ & $V+L$ & 0.1 & 194.2 \\
\hline $205 A$ & $x$ & & & $x$ & & $X$ & $\mathrm{~V}$ & 0.1 & 110 \\
\hline 205B & $\mathrm{x}$ & & & $\mathrm{X}$ & & $X$ & $\mathrm{~L}$ & 0.1 & 40 \\
\hline 206 & $x$ & $\mathrm{X}$ & & & & $\mathrm{X}$ & $\mathrm{L}$ & 0.1 & 160 \\
\hline 207A & $X$ & $\mathrm{X}$ & & & & $X$ & V & 0.1 & 189.9 \\
\hline 207B & $\mathrm{X}$ & $\mathrm{X}$ & & & & $X$ & $V+L$ & 0.1 & 160 \\
\hline $208 \mathrm{~A}$ & $\mathrm{x}$ & $x$ & & & & $X$ & $\mathrm{~L}$ & 0.1 & 189.9 \\
\hline $208 C$ & $X$ & $X$ & & & & $X$ & $\mathrm{~L}$ & 70.5 & 376.9 \\
\hline 208D & $x$ & $X$ & & & & $X$ & $L$ & 70.5 & 401.9 \\
\hline $209 A$ & $X$ & $x$ & & & & $X$ & $\mathrm{~L}$ & 70.5 & 403 \\
\hline $209 B$ & $X$ & $X$ & $X$ & & & $X$ & $V+L$ & 70.5 & 563.9 \\
\hline 210 & $x$ & $x$ & $X$ & & & $X$ & $\mathrm{~V}$ & 70.5 & 626.9 \\
\hline $213 \mathrm{~A}$ & $X$ & $x$ & $X$ & $X$ & $X$ & $X$ & V & 70.5 & 900 \\
\hline $213 G$ & $X$ & $x$ & $X$ & $x$ & $x$ & $X$ & $V+L$ & 70.5 & 401.9 \\
\hline 214 & $X$ & $x$ & & & & $X$ & $\mathrm{~L}$ & 70.5 & 401.9 \\
\hline $215 A$ & $X$ & $x$ & $X$ & $X$ & $X$ & $X$ & $\mathrm{~V}$ & 70.5 & 401.9 \\
\hline $215 B$ & $x$ & $x$ & & $x$ & $x$ & $X$ & $V+L$ & 70.5 & 250.9 \\
\hline $216 \mathrm{~A}$ & $X$ & $X$ & & $x$ & $x$ & $X$ & $\mathrm{~L}$ & 70.5 & 252.6 \\
\hline 216B & $X$ & $x$ & & $x$ & $x$ & $X$ & $\mathrm{~L}$ & 70.5 & 120 \\
\hline $216 C$ & $X$ & $X$ & & $x$ & $X$ & $X$ & L & 2 & 118.9 \\
\hline $216 \mathrm{D}$ & $X$ & $X$ & & $X$ & $X$ & $X$ & $V+\mathrm{L}$ & 2 & 40 \\
\hline $217 \mathrm{~A}$ & $x$ & & & $x$ & $x$ & $X$ & $\mathrm{~V}$ & 70.5 & 252.6 \\
\hline 217B & $X$ & & & $X$ & $X$ & $X$ & $V+\mathrm{L}$ & 7 & 128.3 \\
\hline $217 \mathrm{C}$ & $X$ & & & $X$ & $X$ & $X$ & $V+L$ & 7 & 40 \\
\hline 218 & $x$ & & & $x$ & $x$ & $X$ & $\mathrm{~V}$ & 7 & 40 \\
\hline 219 & $X$ & & & $X$ & & $X$ & $L$ & 7 & 40 \\
\hline 221 & & & & & & & $L$ & 0.1 & 40 \\
\hline 222 & $X$ & & & $X$ & & $X$ & V & 0.1 & 40 \\
\hline 223 & $X$ & & & $X$ & & $X$ & $\mathrm{~L}$ & 0.1 & 39.6 \\
\hline 224 & $X$ & & & & & $X$ & V & 0.1 & 39.6 \\
\hline 225 & $X$ & $X$ & & & & $X$ & $\mathrm{~L}$ & 0.1 & 40 \\
\hline 226 & & & & & & & $V+L$ & 0.1 & 40 \\
\hline $227 \mathrm{~A}$ & $x$ & $x$ & & & & $X$ & $\mathrm{~V}$ & 0.1 & 160 \\
\hline 227B & $X$ & $X$ & & & & $X$ & $\mathrm{~L}$ & 0.1 & 40 \\
\hline $228 \mathrm{~A}$ & $X$ & & & $x$ & & $X$ & $\mathrm{~V}$ & 0.1 & 40 \\
\hline $228 \mathrm{~B}$ & $x$ & & & $x$ & & $X$ & $V+L$ & 7 & 120 \\
\hline 229 & $X$ & $x$ & & $X$ & & $X$ & $\mathrm{~L}$ & 12 & 40.5 \\
\hline
\end{tabular}




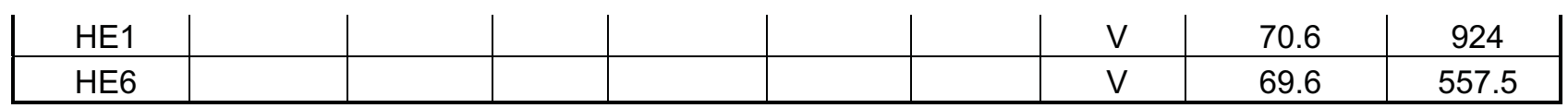

\section{Section 3 (Hydrogen lodide Decomposition)}

Two different processes have been investigated for $\mathrm{HI}$ decomposition. One process, referred to as extractive distillation, uses phosphoric acid to strip $\mathrm{HI}$ from the $\mathrm{HI} / \mathrm{H}_{2} \mathrm{O} / \mathrm{I}_{2}$ ( $\mathrm{HIX}$ ) mixture and to break the $\mathrm{HI} / \mathrm{H}_{2} \mathrm{O}$ azeotrope. The other process is referred to as reactive distillation and involves reacting the $\mathrm{HI} / \mathrm{H}_{2} \mathrm{O} / \mathrm{l}_{2}$ mixture in a reactive bed to effect the separation process and produce hydrogen. Extractive distillation is a proven process, but requires significant amounts of energy and many components to perform the extraction, distillation, concentration, reaction, and separation steps of the process (see Figure 5). The kinetics for reactive distillation are still relatively unknown, but the process can be performed in a single component without requiring concentration of the acid (see Figure 6). For the nth-of-a-kind SI-Based $\mathrm{H}_{2}$ plant design, the $\mathrm{HI}$ decomposition flowsheet is based on the reactive distillation process. One disadvantage of reactive distillation is that there is significant recycle of $\mathrm{HI}$ back to Section 1 , which increases equipment sizes for Section 1.

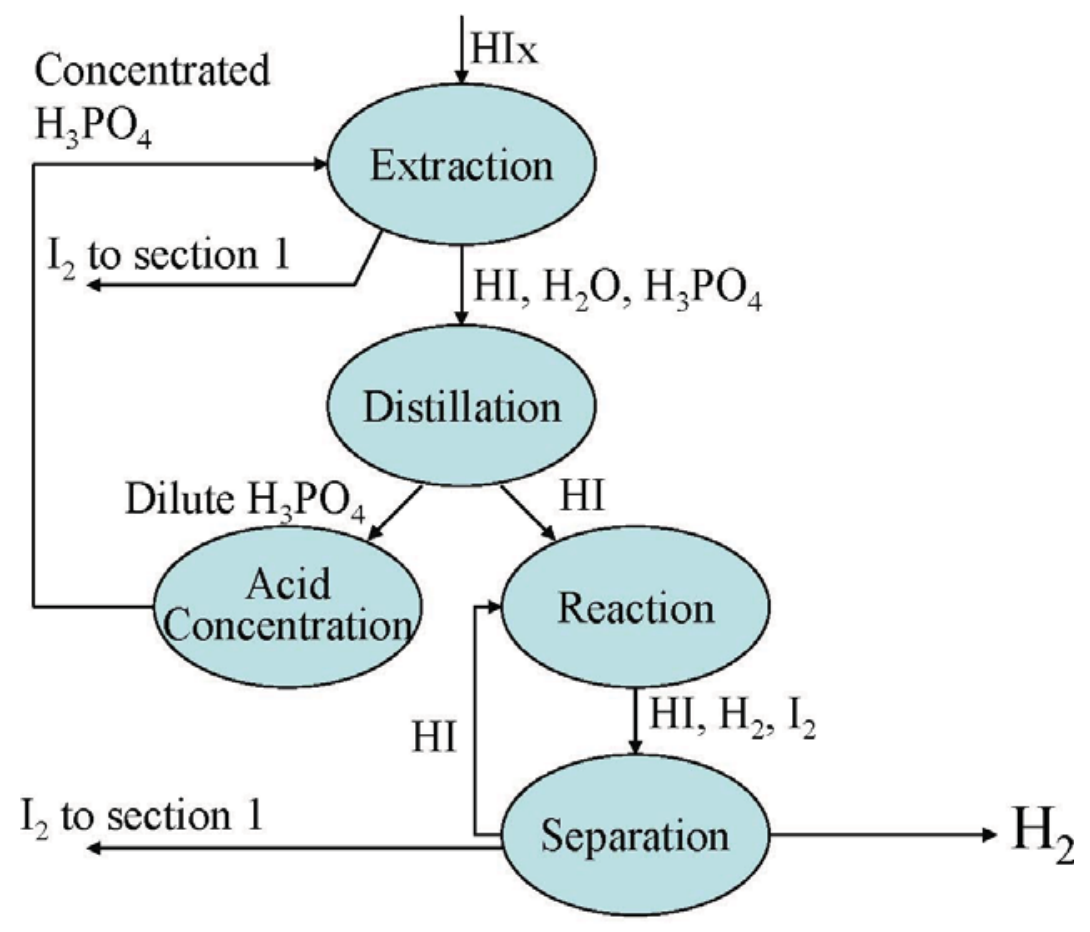

Figure 5 Extractive distillation process diagram 


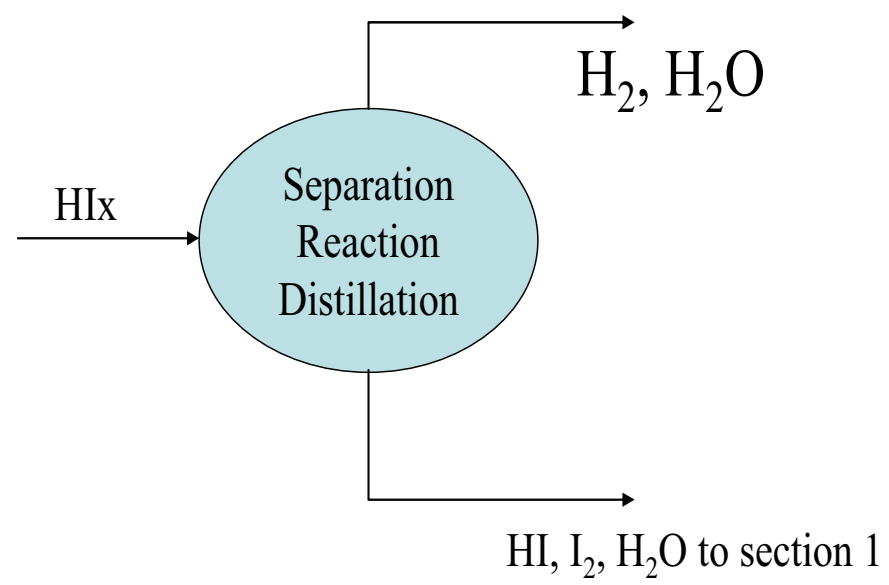

Figure 6 Reactive distillation process diagram

The flowsheet for Section 3 is shown in Figure 7 and the stream compositions are shown in Table 3. The reactive distillation process is performed within a packed-bed distillation column using activated carbon as a catalyst. Significant quantities of heat are required for Section 3, but there are also significant quantities of heat available for recovery within Section 3. Because much of the heat available for recovery is at a temperature lower than required for process operations, heat pumps (using water as the working fluid) are used to transfer the heat from the lower temperature source to the higher temperature sink. The distillation column has a high heat duty in the reboiler and has heat available from the condenser. The first heat pump transfers heat from the condenser to the reboiler at the expense of externally supplied shaft work. Much of the heat is used to break the binding energy of the $\mathrm{HI} / \mathrm{I}_{2} / \mathrm{H}_{2} \mathrm{O}$ complex. For recycled $\mathrm{HI}$, the heat of mixing is recovered and a second heat pump is used to raise the temperature of this stream to that required for heating the distillation column feed. The remaining heat duty of Section 3 is recovered from the decomposer products of Section 2.

The heat pumps consist of a multi-staged steam compressor, a hot heat exchanger complex that transfers heat to the process and condenses steam, an expansion valve in which the condensate is partially flashed and the pressure is lowered, and a cold heat exchanger in which the condensate is evaporated. Mechanical energy drives the compressor and much of this mechanical energy adds internal energy to the steam. The hot heat exchanger network includes the interstage coolers of the compressor as well as the subsequent condenser.

Recovery of the heat of mixing of the $\mathrm{HI} / \mathrm{I}_{2} / \mathrm{H}_{2} \mathrm{O}$ is necessary for process efficiency but does require additional process steps (described below) to produce a stream of pure $\mathrm{I}_{2}$ that is required for operation of the $\mathrm{H}_{2} \mathrm{SO}_{4}$ boost reactor in Section 1. The HIx from Section $1(301 \mathrm{~A})$ is pumped up to the operating pressure of the reactive distillation column (C301) and heated to the required feed temperature in a series of heat exchangers ( $\mathrm{H} 301, \mathrm{H} 302$, and $\mathrm{H} 303)$. Most of the required heat is recovered from cooling hot streams, but a portion of the heat is obtained from Heat Pump 2. The distillation column operates with a vapor product (305) consisting of $\mathrm{HI} / \mathrm{H}_{2} / \mathrm{H}_{2} \mathrm{O}$. The cold side reflux condenser on C301 is HP1-QH, which is the heat input to Heat Pump 1. The 
hot side of the reboiler on C301 is HP2-QC. The heavier liquid phase is nearly pure iodine. This phase is cooled, washed with water in $\mathrm{C} 303$, and returned to Section 1 for use in the $\mathrm{H}_{2} \mathrm{SO}_{4}$ boost reactor. The lighter liquid phase is cooled to the same temperature as the column overhead and then combined with the column overhead (306) to recover the heat of solution from the undecomposed $\mathrm{HI}$. This heat is removed in H304, which is the hot side of HP2-QC and the heat input to Heat Pump 2. HP2-QH, the heat output of Heat Pump 2, is the hot side of $\mathrm{H} 303$ and the final preheat of the still feed. The two-phase stream leaving H304 is separated in S301. The vapor phase contains the hydrogen product gas. This stream is cooled in $\mathrm{H} 308$ and the condensate is removed in S302. The hydrogen is then washed with water in C302 to yield the final hydrogen product. The condensate from S302 consists of two liquid phases. The heavier phase is primarily iodine and is washed in $\mathrm{C} 303$ for use in the $\mathrm{H}_{2} \mathrm{SO}_{4}$ boost reactor of Section 1. The lighter phase is mostly water and is combined with the lower phase from $\mathrm{C} 302$, which is also mostly water. These two streams function as the wash for C303.

Pure water is not very effective at washing iodine out of hydrogen, but iodine is very soluble in $\mathrm{HI}$. For this reason, a small amount of the distillation overhead (313A) is split from the main flow (305), cooled, and then added back to the wash column (C301) at an intermediate stage.

The liquid phase from S301 is split for heat recovery. Part of the heat is recovered into the column feed and the remainder is cooled in $\mathrm{H} 305$, which is the hot side of $\mathrm{H} 202$ in Section 2. 


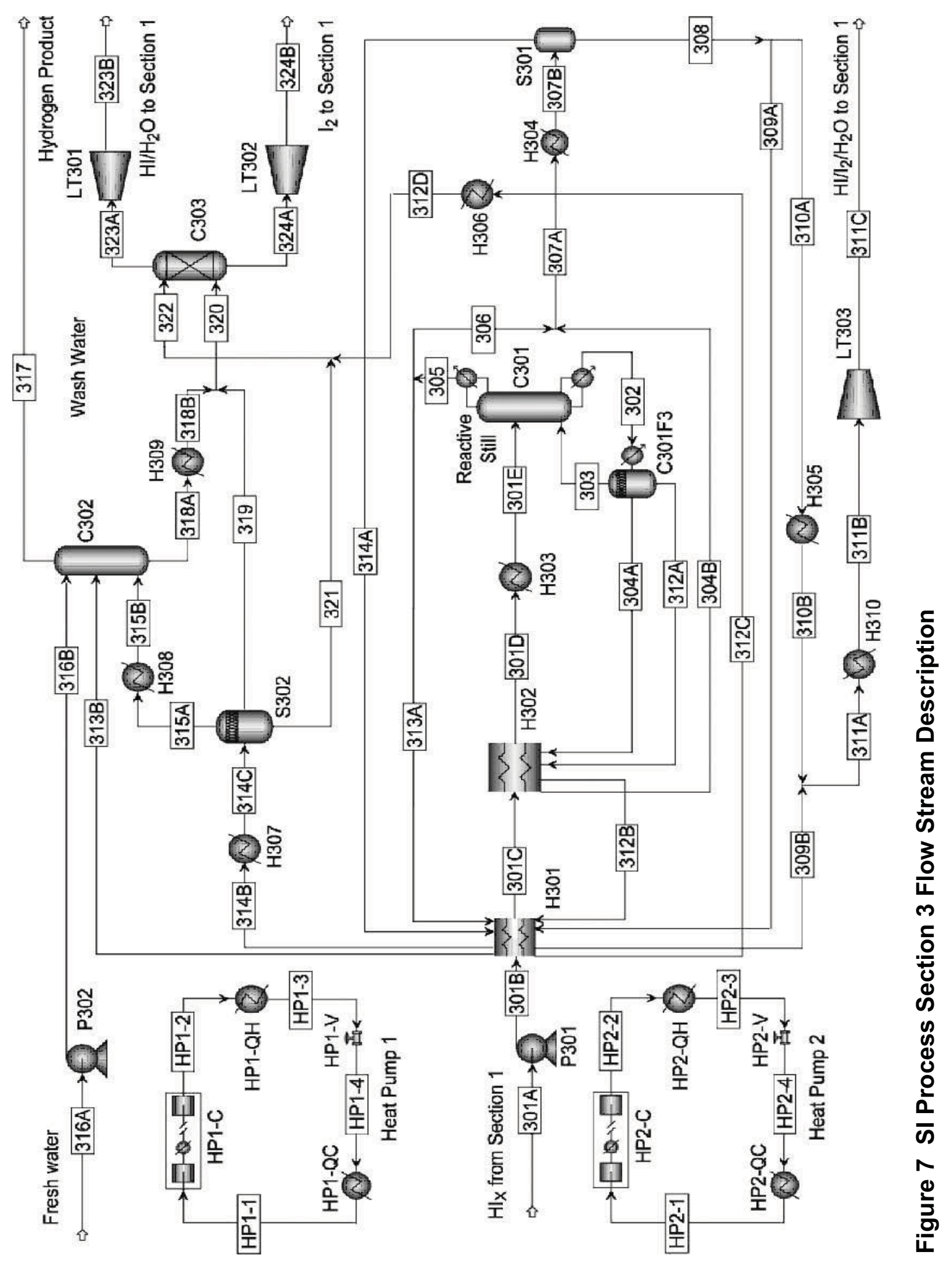


Table 3 Section 3 stream components

\begin{tabular}{|c|c|c|c|c|c|c|c|}
\hline Stream ID & & & & Sp & es Pres & & \\
\hline & $\mathrm{H}_{2} \mathrm{O}$ & $I_{2}$ & HI & $\mathrm{H}_{2}$ & Phase & Pressure (Bar) & Temp. $\left({ }^{\circ} \mathrm{C}\right)$ \\
\hline $301 \mathrm{~A}$ & $x$ & $x$ & $x$ & & $\mathrm{~L}$ & 1.85 & 119.85 \\
\hline $301 \mathrm{~B}$ & $x$ & $x$ & $x$ & & $\mathrm{~L}$ & 40.00 & 123.07 \\
\hline $301 \mathrm{C}$ & $x$ & $\mathrm{X}$ & $x$ & & $\mathrm{~L}$ & 40.00 & 247.17 \\
\hline $301 \mathrm{D}$ & $x$ & $\mathrm{X}$ & $x$ & & $\bar{L}$ & 40.00 & 269.87 \\
\hline $301 \mathrm{E}$ & $x$ & $x$ & $x$ & & $V+L$ & 40.00 & 282.46 \\
\hline 302 & $x$ & $x$ & $x$ & $x$ & $\mathrm{~L}$ & 40.00 & 289.69 \\
\hline 303 & $\mathrm{X}$ & $\mathrm{X}$ & $\mathrm{X}$ & $\mathrm{X}$ & $\mathrm{V}$ & 40.00 & 289.06 \\
\hline $304 \mathrm{~A}$ & $x$ & $x$ & $x$ & & $\bar{L}$ & 40.00 & 289.06 \\
\hline $304 \mathrm{~B}$ & $x$ & $\mathrm{X}$ & $x$ & & $\mathrm{~L}$ & 40.00 & 257.17 \\
\hline 305 & $x$ & $X$ & $x$ & $X$ & $\mathrm{~V}$ & 40.00 & 262.17 \\
\hline 306 & $x$ & $x$ & $x$ & $x$ & $\mathrm{~V}$ & 40.00 & 262.17 \\
\hline $307 A$ & $x$ & $\mathrm{X}$ & $x$ & $\mathrm{X}$ & $V+L$ & 40.00 & 271.06 \\
\hline $307 \mathrm{~B}$ & $x$ & $X$ & $X$ & $\mathrm{X}$ & $V+L$ & 40.00 & 257.17 \\
\hline 308 & $x$ & $\mathrm{X}$ & $x$ & $\mathrm{X}$ & $\mathrm{L}$ & 40.00 & 257.17 \\
\hline $309 \mathrm{~A}$ & $x$ & $\mathrm{X}$ & $x$ & $X$ & $\mathrm{~L}$ & 40.00 & 257.17 \\
\hline $309 B$ & $x$ & $x$ & $x$ & $x$ & $L$ & 40.00 & 139.01 \\
\hline $310 \mathrm{~A}$ & $x$ & $X$ & $X$ & $X$ & $\mathrm{~L}$ & 40.00 & 257.17 \\
\hline $310 \mathrm{~B}$ & $x$ & $X$ & $X$ & $X$ & $\mathrm{~L}$ & 40.00 & 139.01 \\
\hline $311 \mathrm{~A}$ & $X$ & $X$ & $X$ & $X$ & $\mathrm{~L}$ & 40.00 & 139.01 \\
\hline 311B & $x$ & $X$ & $X$ & $X$ & $L$ & 40.00 & 120 \\
\hline $311 \mathrm{C}$ & $x$ & $x$ & $x$ & $X$ & $L$ & 7.00 & 118.78 \\
\hline $312 \mathrm{~A}$ & $x$ & $X$ & $X$ & & $\mathrm{~L}$ & 40.00 & 289.06 \\
\hline $312 B$ & $X$ & $X$ & $X$ & & $\mathrm{~L}$ & 40.00 & 257.17 \\
\hline $312 \mathrm{C}$ & $x$ & $X$ & $X$ & & $\mathrm{~L}$ & 40.00 & 139.01 \\
\hline $313 A$ & $x$ & $x$ & $x$ & $X$ & $\mathrm{~V}$ & 40.00 & 262.17 \\
\hline $313 B$ & $X$ & $X$ & $x$ & $X$ & $V+L$ & 40.00 & 139.01 \\
\hline $314 \mathrm{~A}$ & $x$ & $X$ & $X$ & $X$ & $\mathrm{~V}$ & 40.00 & 257.17 \\
\hline 314B & $x$ & $X$ & $X$ & $X$ & $V+L$ & 40.00 & 139.01 \\
\hline $314 \mathrm{C}$ & $x$ & $X$ & $X$ & $X$ & $V+L$ & 40.00 & 120 \\
\hline $315 \mathrm{~A}$ & $x$ & $X$ & & $X$ & $\mathrm{~V}$ & 40.00 & 120 \\
\hline $315 B$ & $x$ & $X$ & & $X$ & $V+L$ & 40.00 & 40 \\
\hline $316 \mathrm{~A}$ & $x$ & & & & $\mathrm{~L}$ & 1.01 & 25 \\
\hline $316 \mathrm{~B}$ & $x$ & & & & $\mathrm{~L}$ & 40.00 & 27.26 \\
\hline 317 & $x$ & & & $X$ & $\mathrm{~V}$ & 40.00 & 28.82 \\
\hline $318 \mathrm{~A}$ & $x$ & $X$ & $X$ & $X$ & $\mathrm{~L}$ & 40.00 & 42.97 \\
\hline 318B & $x$ & $X$ & $X$ & $X$ & $V+L$ & 40.00 & 110 \\
\hline 319 & $x$ & $X$ & $X$ & $X$ & $\mathrm{~L}$ & 40.00 & 120 \\
\hline 320 & $x$ & $X$ & $x$ & $X$ & $V+L$ & 40.00 & 117.69 \\
\hline 321 & $x$ & $x$ & $x$ & $X$ & $\mathrm{~L}$ & 40.00 & 120 \\
\hline 322 & $x$ & $X$ & $X$ & $X$ & $\mathrm{~L}$ & 40.00 & 118.27 \\
\hline $322 \mathrm{D}$ & $x$ & $X$ & $X$ & & $\mathrm{~L}$ & 40.00 & 120 \\
\hline $323 \mathrm{~A}$ & $X$ & $X$ & $X$ & $X$ & $\mathrm{~L}$ & 40.00 & 120.55 \\
\hline 323B & $x$ & $X$ & $X$ & $X$ & $L$ & 7.00 & 120.39 \\
\hline $324 \mathrm{~A}$ & $X$ & $X$ & $X$ & $X$ & $\mathrm{~L}$ & 40.00 & 118.04 \\
\hline 324B & $x$ & $x$ & $x$ & $X$ & $\mathrm{~L}$ & 7.00 & 115.57 \\
\hline
\end{tabular}




\begin{tabular}{|c|c|c|c|c|c|c|c|} 
HP1-1 & $X$ & & & & $V$ & 44.77 & 257.12 \\
\hline HP1-2 & $X$ & & & & $V$ & 71.60 & 288.46 \\
\hline HP1-3 & $X$ & & & & $L$ & 71.60 & 287.4 \\
\hline HP1-4 & $X$ & & & & $V+L$ & 44.77 & 257.12 \\
\hline HP2-1 & $X$ & & & $V$ & 41.21 & 252.13 \\
\hline HP2-2 & $X$ & & & & $V$ & 79.50 & 295.69 \\
\hline HP2-3 & $X$ & & & & $L$ & 79.50 & 294.6 \\
\hline HP2-4 & $X$ & & & & $\mathrm{~V}+\mathrm{L}$ & 41.21 & 252.13 \\
\hline
\end{tabular}

\section{Integrated Lab Scale Experiments}

The Sulfur-lodine (S-I) thermochemical cycle is one of the baseline production methods that is being investigated under the Nuclear Hydrogen Initiative (NHI). The current objective is to conduct an integrated lab scale (ILS) experiment in order to provide a technical basis for the assessment of the viability of the S-I cycle for nuclear hydrogen production. This will serve as a stepping stone for future pilot and engineering scale demonstrations. The overall ILS project objectives were as follows:

- Complete the open-loop component reaction experiments that demonstrate the key chemical processes in stand alone mode in engineering materials of construction.

- Perform closed-loop lab scale hydrogen production experiments under prototypic conditions to provide the technical basis for evaluating the S-I cycle for nuclear hydrogen production.

- Develop a process flowsheet for pilot scale plants that can be used to project process efficiency and preliminary costs.

The development of the S-I cycle ILS loop has been performed as an international effort involving the US Labs and Industry and the Commissariat à I'Énergie Atomique (CEA) of France. The S-I cycle consists of three reaction sections which are currently being developed by three different organizations. Sandia National Laboratory (SNL) developed the high temperature sulfuric acid decomposition section, General Atomics (GA) developed the HI decomposition (hydrogen generation) section, and the CEA developed the primary Bunsen reaction section. These three sections along with a fourth interface section have been integrated together to demonstrate closed loop operation of the S-I cycle. General Atomics was chosen by DOE to host the ILS loop. 


\section{Brief description of the ILS loop}

The ILS loop is made up of four interconnecting sections:

Section I (Bunsen Reaction)

Section II (Sulfuric Acid Decomposition)

$\mathrm{SO}_{2}+2 \mathrm{H}_{2} \mathrm{O}+\mathrm{I}_{2} \rightarrow \mathrm{H}_{2} \mathrm{SO}_{4}+2 \mathrm{HI}$

Section III (HI Decomposition)

$\mathrm{H}_{2} \mathrm{SO}_{4} \rightarrow \mathrm{H}_{2} \mathrm{O}+\mathrm{SO}_{2}+1 / 2 \mathrm{O}_{2}$

Interface section - buffer tanks for storage and feed between the process sections

Each section is constructed on an individual skid (pallet) and all the associated process equipment is enclosed within. The walls and the tops of the skids are constructed from Lexan or similar material. The bases are made from steel and are shaped to contain any chemical spill. The four sections are linked together through connection pipes that transport the process chemical streams. A 3-D schematic of the ILS loop layout is shown in Figure 8. The three process sections are connected to each other via the interface skid, which holds the storage and feed tanks for the circulating reaction fluids. With this design, each individual section can operate on its own without the need for concurrent operation of another section to either supply or receive the process chemicals. This helps to ensure the safe operation of the individual sections.

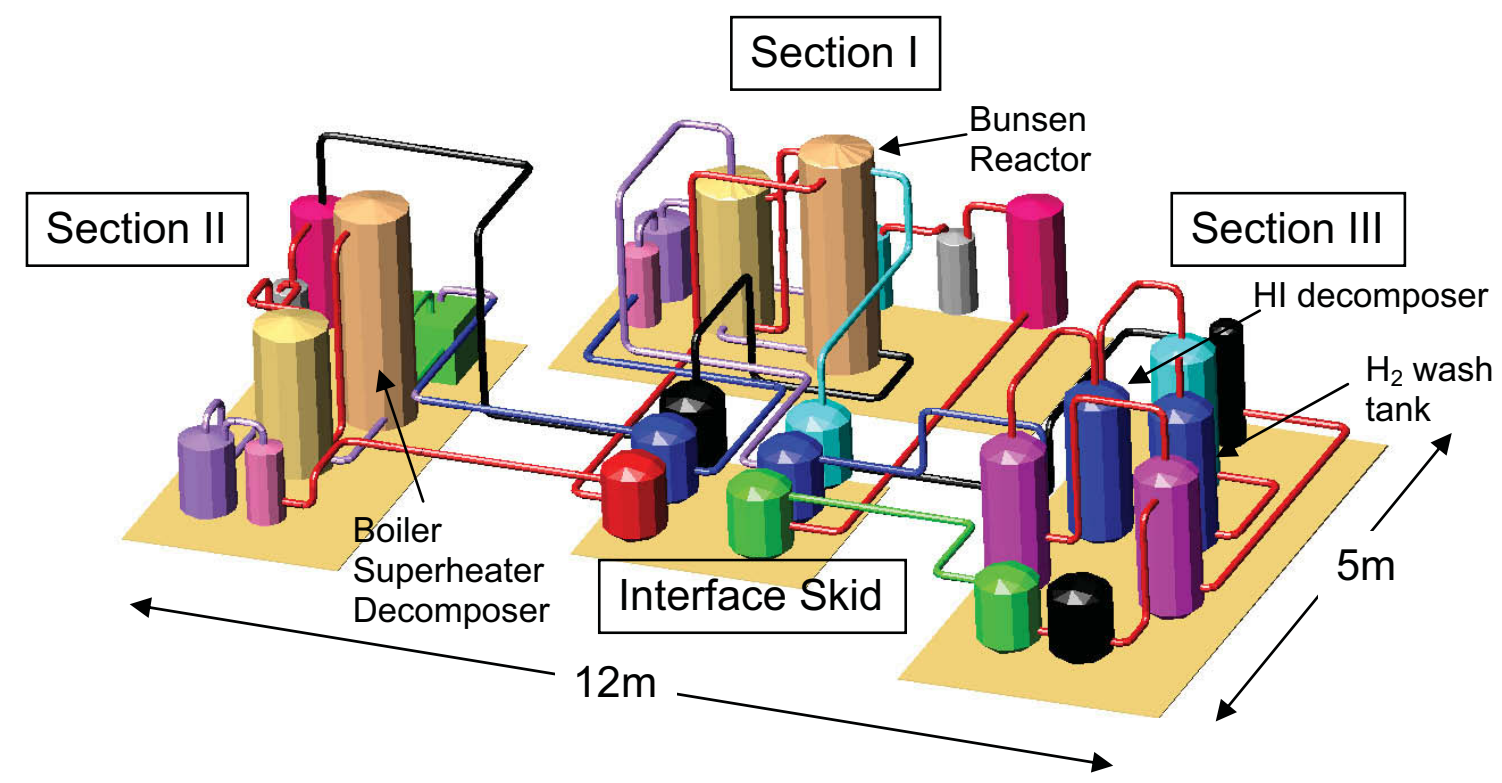

Figure 8 A schematic showing the four different skids of the ILS loop.

\section{S-I Cycle Integrated Lab Scale Experiment Schedule}

The ILS experiments proceeded in stages as follows: 
- Year 1 FY06 -- R\&D to support the construction and testing of the integrated lab scale sections

- Year 2 FY07-Testing of individual skid mounted sections at each site, ship and assemble sections at the GA integrated lab scale experiment site

- Years 3 \& 4 FY08/09- Conduct integrated lab-scale hydrogen production experiment program

In addition to the development of process chemistry, materials testing and diagnostic development for each section, this project has involved specific lab scale integration activities to develop S-I control systems for closed loop operations, section interface components and the safety documentation and approvals to conduct the lab scale experiments. The overall integrated lab scale equipment is shown in Figure 9.

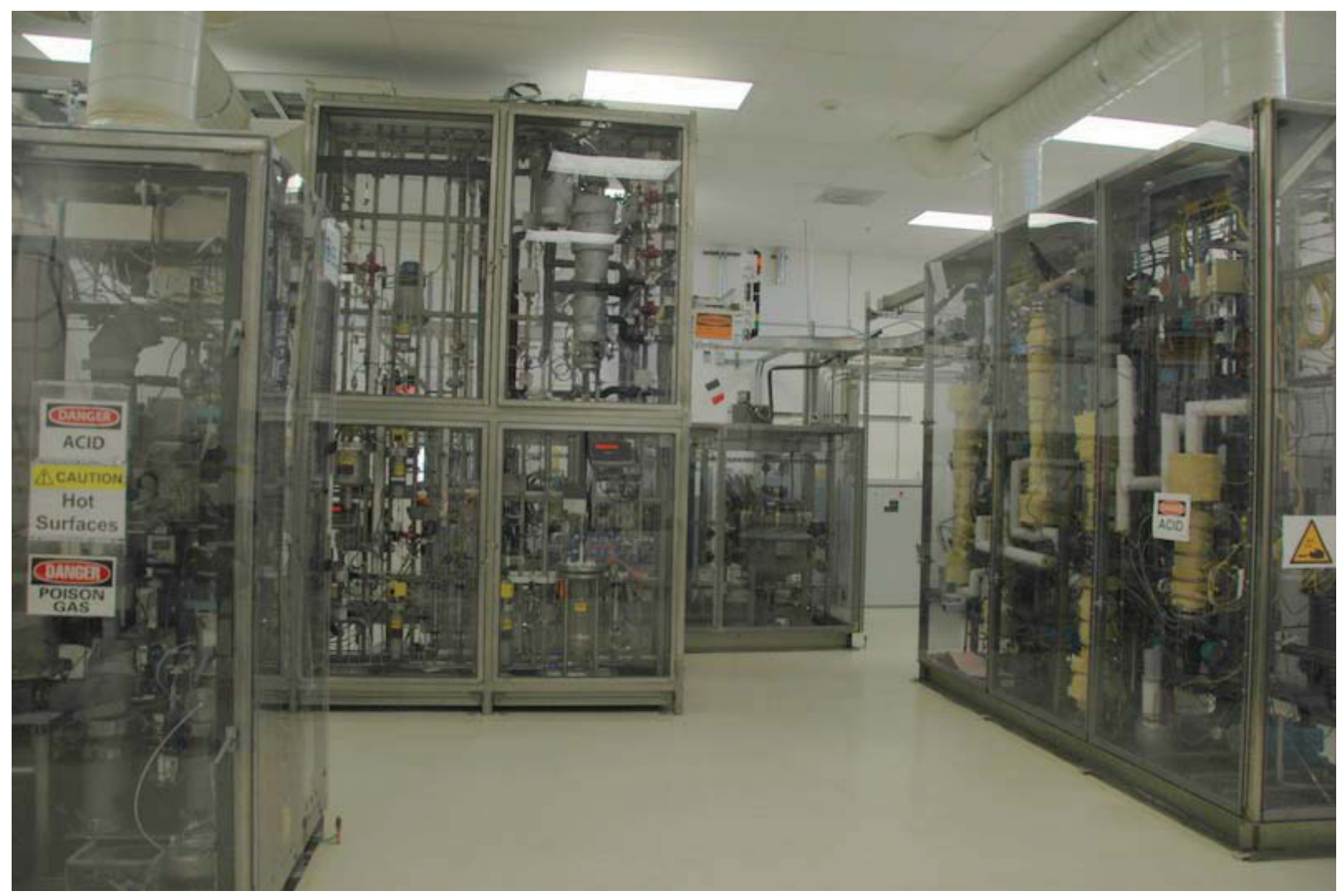

Figure 9 Integrated Lab Scale (ILS) experiment

\section{Design Criteria for the ILS}

The ILS experiment has been designed to meet the following criteria:

- Demonstrate the three component steps of the Sulfur-lodine process

- Demonstrate the operation of the integrated equipment

- Generate hydrogen at a rate of $100 \mathrm{l} / \mathrm{hr}$ 
- Equipment constructed from engineering materials

- Operated at nominal temperature and pressures $\left(120-850^{\circ} \mathrm{C}\right.$ and up to 20 bar)

- Experimental enclosures constructed to ensure safe operation and containment of any possible leaks or spills

- Implement a control system which allows for the remote operation of the equipment and data logging of the process conditions

\section{Bunsen Reaction Skid Description (Section 1)}

The Bunsen section reacts water with iodine and sulfur dioxide to produce two acid phases, the light sulfuric acid phase and the heavy hydriodic acid phase. In addition to producing the two acid phases, the Bunsen section also separates oxygen from the sulfur dioxide produced by Section 2 . The flowsheet for the Bunsen section skid, scaled to $1 \mathrm{~mole} / \mathrm{hr} \mathrm{H}_{2}$ production, is shown in Figure 10.

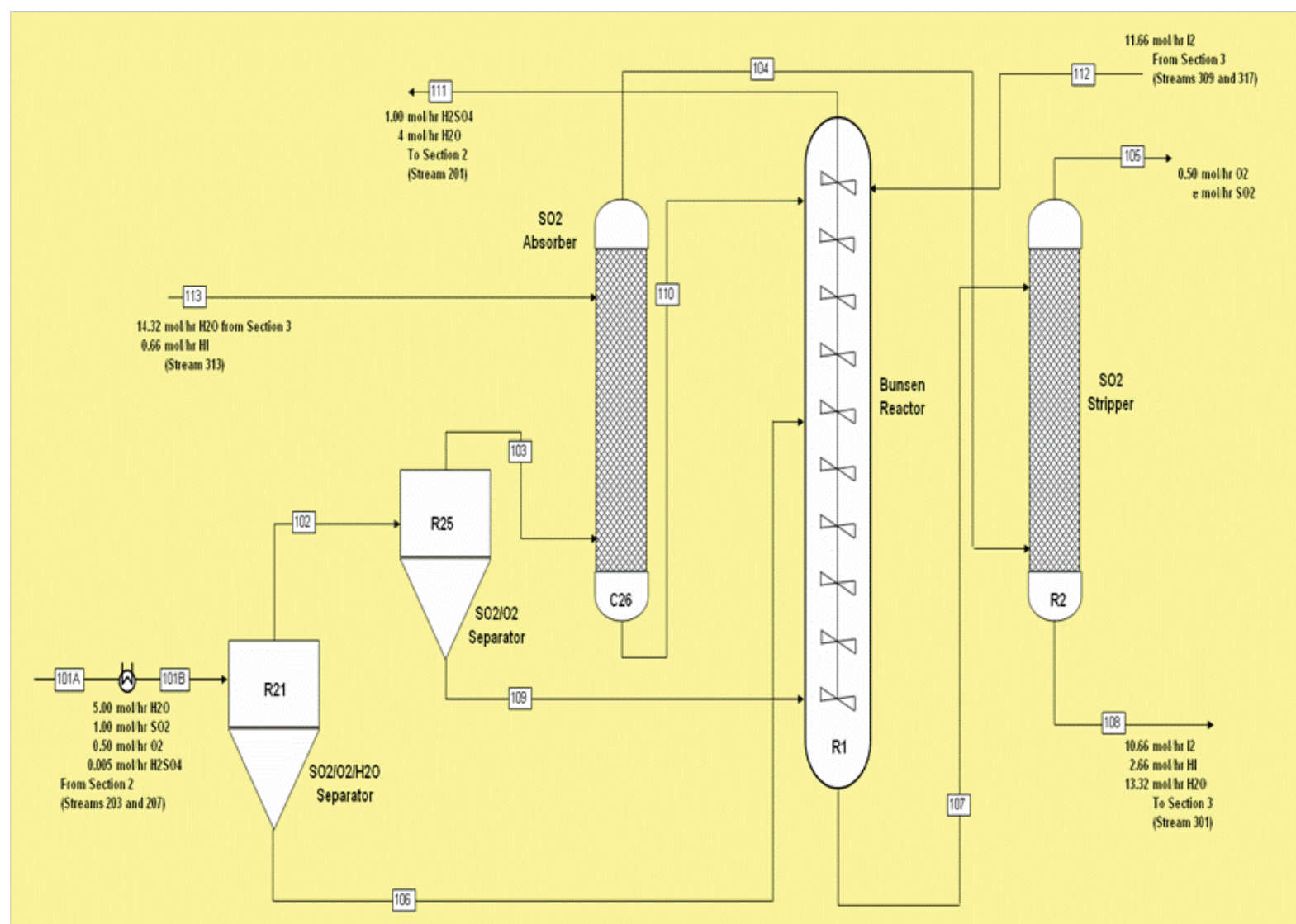

Figure 10 Bunsen section flowsheet

The Bunsen section equipment, shown in Figure 11. 


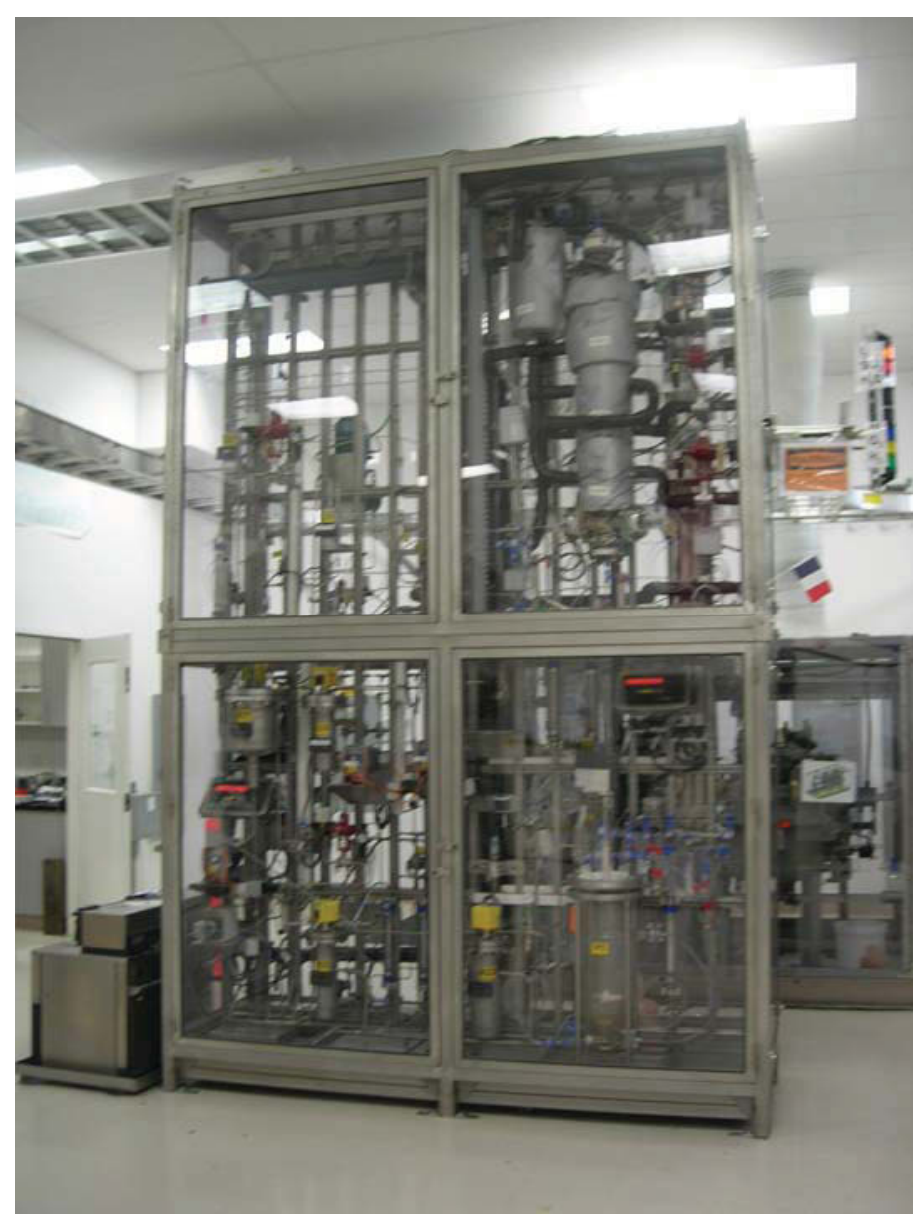

Figure 11 Bunsen section skid

\section{Process Description}

In the Bunsen section iodine and $\mathrm{SO}_{2}$ react with $\mathrm{H}_{2} \mathrm{O}$ to form $\mathrm{HI}$ and $\mathrm{H}_{2} \mathrm{SO}_{4}$. The reaction is exothermic and takes place at medium temperature $\left(\sim 120^{\circ} \mathrm{C}\right)$. The co-current heat exchanger =reactor approach was demonstrated by GA in 1981, and subsequently by JAERI in 2003 , and has been the basis for most analyses. An alternative flow sheet is currently being considered by CEA involving a counter current three phase reactor. $\mathrm{O}_{2}$, which does not participate to the reaction, is removed from the input gases. This requires compression and cooling to separate $\mathrm{SO}_{2}$ and $\mathrm{O}_{2}$. The Bunsen reaction is carried out in a single reactor. This approach has a higher theoretical efficiency than the original 1984 GA model. The basic flow sheet options, considered for the Bunsen section, are shown in Figure 12. CEA has added three alternative features to the former flow sheet:

- $\quad$ Addition of a reactor for boosting the $\mathrm{HI}$ content of the dense liquid phase. - $\quad$ Grouping the main Bunsen reactor and the $\mathrm{H}_{2} \mathrm{SO}_{4}$ and $\mathrm{HI}$ boost reactors into a single counter-current reactor.

- Separation of $\mathrm{SO}_{2}$ and $\mathrm{O}_{2}$ before introduction into the Bunsen reactor. 
With this design, four basic operations (three reactors and a phase separator) are combined in a single device operating in the counter-current mode.

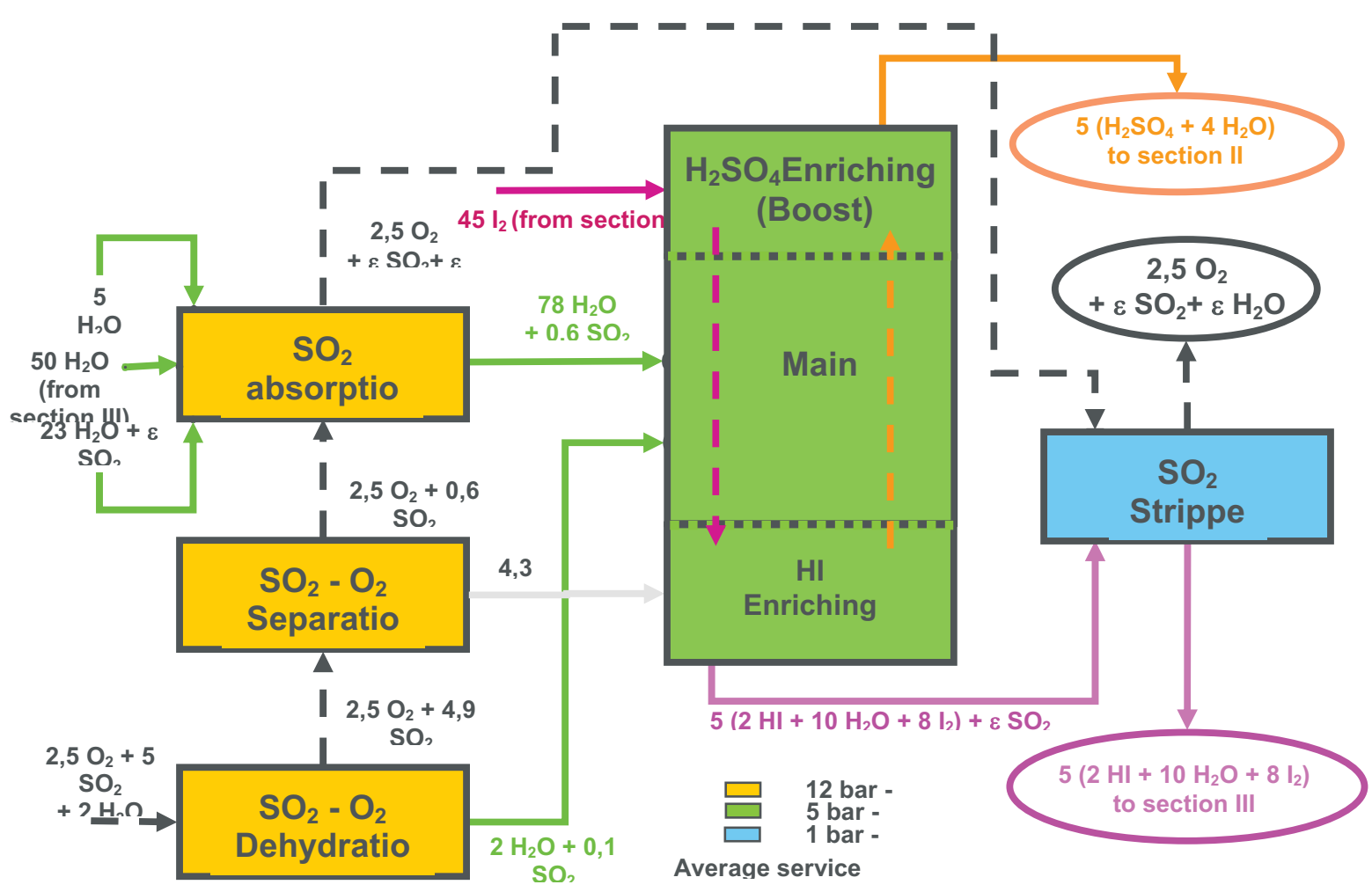

Figure 12 Bunsen Section. CEA proposed flow sheet.

Two criteria, reaction time and heat transfer, must be taken into account: Reaction time must be minimized to avoid side reactions but heat transfer needs sufficient exchange surface to extract the heat of reaction. The combination of these two constraints led to the choice of an apparatus consisting of a set of continuously stirred reactors installed vertically in series in the form of a mechanically stirred column-type liquid-liquid contactor (Kühni contactor).

Mixers in each section of the reactor maintain conditions required for the chemical reaction. They also promote heat transfer through the walls of the reactor, which is required for the exothermic reaction to proceed. The reactor also incorporates the phase separators. The remaining gas phase must be separated at the top the reactor. The separation of the two liquid phases can occur at either the top or bottom of the reactor, but the reactor construction is simpler if this separation takes place at the top. Due to the highly corrosive properties of the reactants, the materials used for the components of the reactor are glass coated steel, fluorinated polymer, zirconium and tantalum at specific locations. 
The operating principles are the following:

$\mathrm{SO}_{2}$ is fed at the bottom of the reactor and flows upward. The $\mathrm{I}_{2}$ rich heavy phase flows downward. $\mathrm{SO}_{2}$ reacts with $\mathrm{I}_{2}$ and water forming $\mathrm{H}_{2} \mathrm{SO}_{4}$ and $\mathrm{HI}_{2} \mathrm{H}_{2} \mathrm{SO}_{4}$ separates from the iodine as a separate liquid phase, extracting additional water from the $\mathrm{HIx}$ as it does so. The light $\mathrm{H}_{2} \mathrm{SO}_{4}$ phase also rises against the downward flowing heavy phase.

The central reaction zone is the location of the main reactor. An aqueous phase fed into this zone mixes with the rising $\mathrm{H}_{2} \mathrm{SO}_{4}$ phase and flows upwards in contact with the downward flowing $\mathrm{I}_{2}$ phase. Additional $\mathrm{SO}_{2}$ is added with the water so that they both can react with $\mathrm{I}_{2}$ generating $\mathrm{H}_{2} \mathrm{SO}_{4}$ and $\mathrm{HI}$. Some $\mathrm{SO}_{2}$, that entered at the bottom of the reactor remains as a separate vapor phase. $\mathrm{H}_{2} \mathrm{SO}_{4}$ that forms dissolves in the light phase and $\mathrm{HI}$ in the heavy one. The optimal additional water feed location depends on yet unknown thermodynamic and kinetic data.

As the $\mathrm{H}_{2} \mathrm{SO}_{4}$ phase and gaseous $\mathrm{SO}_{2}$ phases continue moving upwards, they are in contact with increasingly purer $\mathrm{I}_{2}$. The pure molten $\mathrm{I}_{2}$ enters at the top of this section. The Bunsen reaction continues in this region with formation of both $\mathrm{HI}$ and $\mathrm{H}_{2} \mathrm{SO}_{4} . \mathrm{H}_{2} \mathrm{SO}_{4}$ dissolves in the light phase and $\mathrm{HI}$ in the heavy one. The dissolution of $\mathrm{HI}$ in $\mathrm{I}_{2}$ favors the extraction of water from the $\mathrm{H}_{2} \mathrm{SO}_{4}$ phase and its incorporation into the heavy phase.

Since the Bunsen reaction takes place in the liquid phase, it is necessary to dissolve the $\mathrm{SO}_{2}$ in the reaction medium and maintain the highest possible $\mathrm{SO}_{2}$ partial pressure. The reaction temperature selected is $120^{\circ} \mathrm{C}$, which results in a high $\mathrm{SO}_{2}$ vapor pressure - close to 30 bars. To favor dissolution, the reactor will operate at a pressure of 5 bars. These considerations suggest prior separation of the $\mathrm{SO}_{2}-\mathrm{O}_{2}-\mathrm{H}_{2} \mathrm{O}$ mixture from section 2. This takes place in three successive phases:

Dehydration of the recycled gas stream from the $\mathrm{H}_{2} \mathrm{SO}_{4}$ decomposition section: the gas stream is isobarically cooled to $25^{\circ} \mathrm{C}$.

$\mathrm{SO}_{2}-\mathrm{O}_{2}$ separation: The dried gas is adiabatically compressed to 12 bars and cooled to $25^{\circ} \mathrm{C}$. Most of the $\mathrm{SO}_{2}$ is condensed and separated from the oxygen which contains some residual $\mathrm{SO}_{2}$.

Stripping residual $\mathrm{SO}_{2}$ from the gas stream: The oxygen leaving the previous stage is washed with water in a counter-current packed column.

\section{Design of the ILS Bunsen Section}

The pilot unit has been sized for the production of 5 moles of hydrogen per hour $\left(112 ~ N L . h^{-1}\right)$. The overall reaction is the following: 


$$
45 \mathrm{I}_{2}+5 \mathrm{SO}_{2}+80 \mathrm{H}_{2} \mathrm{O}=5\left(2 \mathrm{HI}+10 \mathrm{H}_{2} \mathrm{O}+8 \mathrm{I}_{2}\right)+5\left(\mathrm{H}_{2} \mathrm{SO}_{4}+4 \mathrm{H}_{2} \mathrm{O}\right)
$$

The pilot unit, proposed for the Bunsen reaction, must enable tests to be carried out for characterization of the process in stand-alone mode and be suitable for integration in a system constituting a demonstrator for the entire S-I loop. These constraints have the following consequences:

In stand-alone mode, the quantities of molecular iodine used are substantial. The flow per unit mass for decomposition represents $1.28 \mathrm{~kg} \cdot \mathrm{h}^{-1}$ and the excess stream close to $11.5 \mathrm{~kg} \cdot \mathrm{h}^{-1}$. Recycling of the iodine is therefore essential to carry out the tests under acceptable conditions. A distillation column has been designed to allow online iodine recycling. Aqueous $\mathrm{HI}$ is batch treated (inverted Bunsen reaction) to recover iodine.

Ease of integration in the S-I loop: The equipment supplying the loop with reagents must be designed to accept the recycled streams from the acid decomposition sections. The outlet products must be compatible with the decomposition sections.

\section{Sulfuric Acid Decomposition Skid Description (Section 2)}

The sulfuric acid skid, shown in Figure 13, has been installed and tested at a production rate comparable to $300 \mathrm{l} / \mathrm{hr} \mathrm{H}_{2}$ production. 


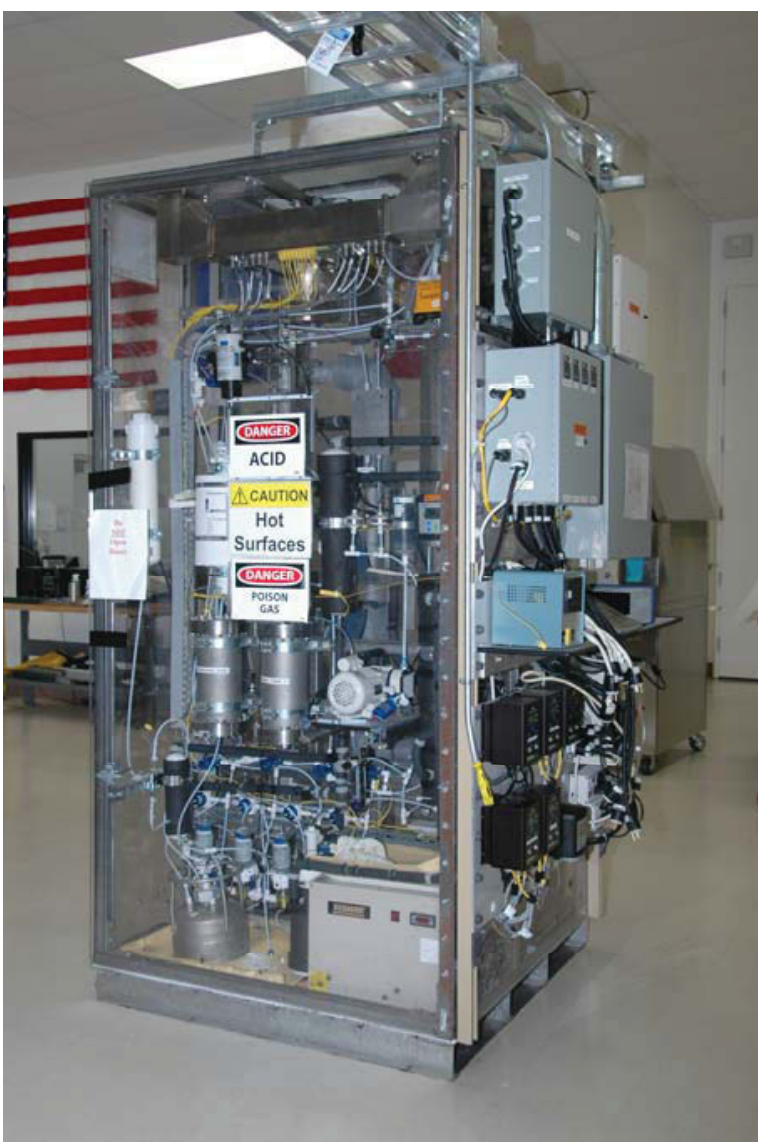

Figure 13 Sulfuric acid decomposition skid

The sulfuric acid decomposition section (skid 2), concentrates, heats and catalytically decomposes the acid to sulfur dioxide, oxygen, and water. The sulfur dioxide and water produced in the process is combined with iodine and water in the Bunsen section (skid 1) to produce hydrogen iodide and sulfuric acid. The sulfuric acid is recycled back to the sulfuric acid decomposition skid. For the sulfuric acid decomposer skid to operate in the ILS, the following design objectives must be met:

- generate sulfur dioxide equivalent to a hydrogen production rate of $>100$ liter/hr (equivalent to $>100$ liter/hr hydrogen) from input acid at concentrations of $20 \mathrm{~mol} \%$ or higher,

- maintain a decomposition temperature of $850^{\circ} \mathrm{C}$ and pressures up to nominally 3 bar,

- perform safely with redundent safety systems for containing $\mathrm{SO}_{2}$ releases, and

- utilize corrosion-resistant materials of construction to allow extended operations. 


\section{Decomposition Skid Details}

A schematic of the $\mathrm{H}_{2} \mathrm{SO}_{4}$ decomposition skid developed for the ILS experiments at GA is shown in Figure 14. Dilute acid from the Bunsen skid enters the concentrator where the acid is concentrated from $20 \mathrm{~mol} \%$ to about $40 \mathrm{~mol} \%$. The concentrated acid is collected into the Concentrated Acid Tank, and the water vapor is condensed and collected in Water Tank 1. The acid is then combined with unreacted acid from the bayonet and introduced into the base of the bayonet. In the bayonet the acid is heated to $850^{\circ} \mathrm{C}$ and partially decomposed. The gaseous decomposition products of $\mathrm{SO}_{2}, \mathrm{O}_{2}$, and $\mathrm{H}_{2} \mathrm{O}$ flow out the inner channel and most of the heat content is recuperated to the incoming acid. Undecomposed acid is condensed, collected in the Recycle Acid Tank, and recycled back to the bayonet. The gas stream is then cooled to condense liquid water into Water Tank 2. A gas stream consisting of $\mathrm{SO}_{2}$ and $\mathrm{O}_{2}$, and a liquid water stream from Water Tanks 1 and 2 are the products of the $\mathrm{H}_{2} \mathrm{SO}_{4}$ decomposition skid. These two streams are sent to the Bunsen skid. 


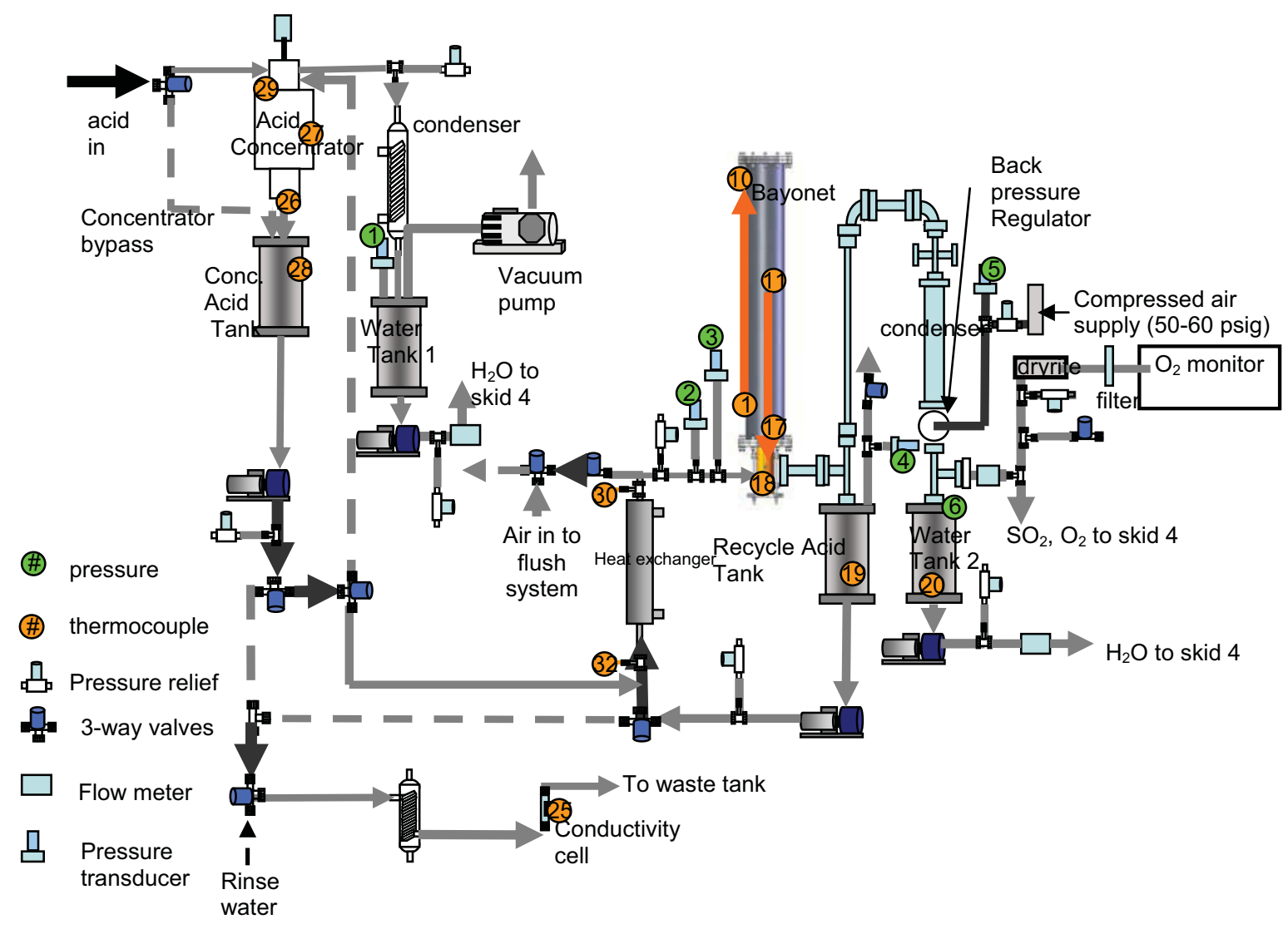

Figure14 Schematic layout of the $\mathrm{H}_{2} \mathrm{SO}_{4}$ decomposition section skid. (The orange and green shaded circles correspond to the locations of thermocouples and pressure transducers, respectively. The shapes of the bayonet, concentrator, water tank 1 , water tank 2 , recycle acid tank, and the concentrated acid tank in this Figure are drawn to be similar to the actual units shown in Figures 15 and 16).

The entire $\mathrm{H}_{2} \mathrm{SO}_{4}$ decomposition skid is contained within a Lexan enclosure that has a $4 \mathrm{ft}$ by $4 \mathrm{ft}$ base, and is $8 \mathrm{ft}$ high. The two access sides of the skid are shown in Figures 15 and 16, respectively. The outer enclosure is connected to the GA ventilation system, which continuously draws $800 \mathrm{cfm}$ from within the enclosure through a charcoal filter before releasing the gas to the atmosphere.

Within the outer enclosure the components are segregated into two different areas of the skid; those containing liquid acid solutions shown in Figure 14, and those containing $\mathrm{SO}_{2}$ shown in Figure 15. Previous tests at SNL showed that $\mathrm{SO}_{2}$ is highly permeable through Teflon and Viton. To minimize the possible releases of $\mathrm{SO}_{2}$ two design features were added to the system. First, glass-lined steel was used on the outlet side of the bayonet to the product outlet to minimize the release of $\mathrm{SO}_{2}$ from the unit itself. Second, an inner Lexan enclosure was constructed within the primary outer enclosure to confine any $\mathrm{SO}_{2}$ permeating from the system. As shown in Figure 16, the bayonet and other $\mathrm{SO}_{2}$ containing 
components were arranged within an inner confinement enclosure. Other components that contain only acid solutions are arranged within the primary outer skid enclosure. Any gas leakage from the apparatus within the inner enclosure is contained. The inner enclosure has a separate activated charcoal filter system to absorb small gas leaks. A blower can be remotely operated to vent the inner enclosure to the outer enclosure, which then is vented to the GA ventilation system. Both the inner enclosure volume and the primary outer enclosure volume contain $\mathrm{SO}_{2}$ monitoring systems that allow for continuous readout both at the skid and at the control panel. A third $\mathrm{SO}_{2}$ monitor is mounted on the outside of the skid to detect leakage outside the enclosures. Furthermore, two handheld $\mathrm{SO}_{2}$ monitors are used when running an experiment or servicing the skid, 


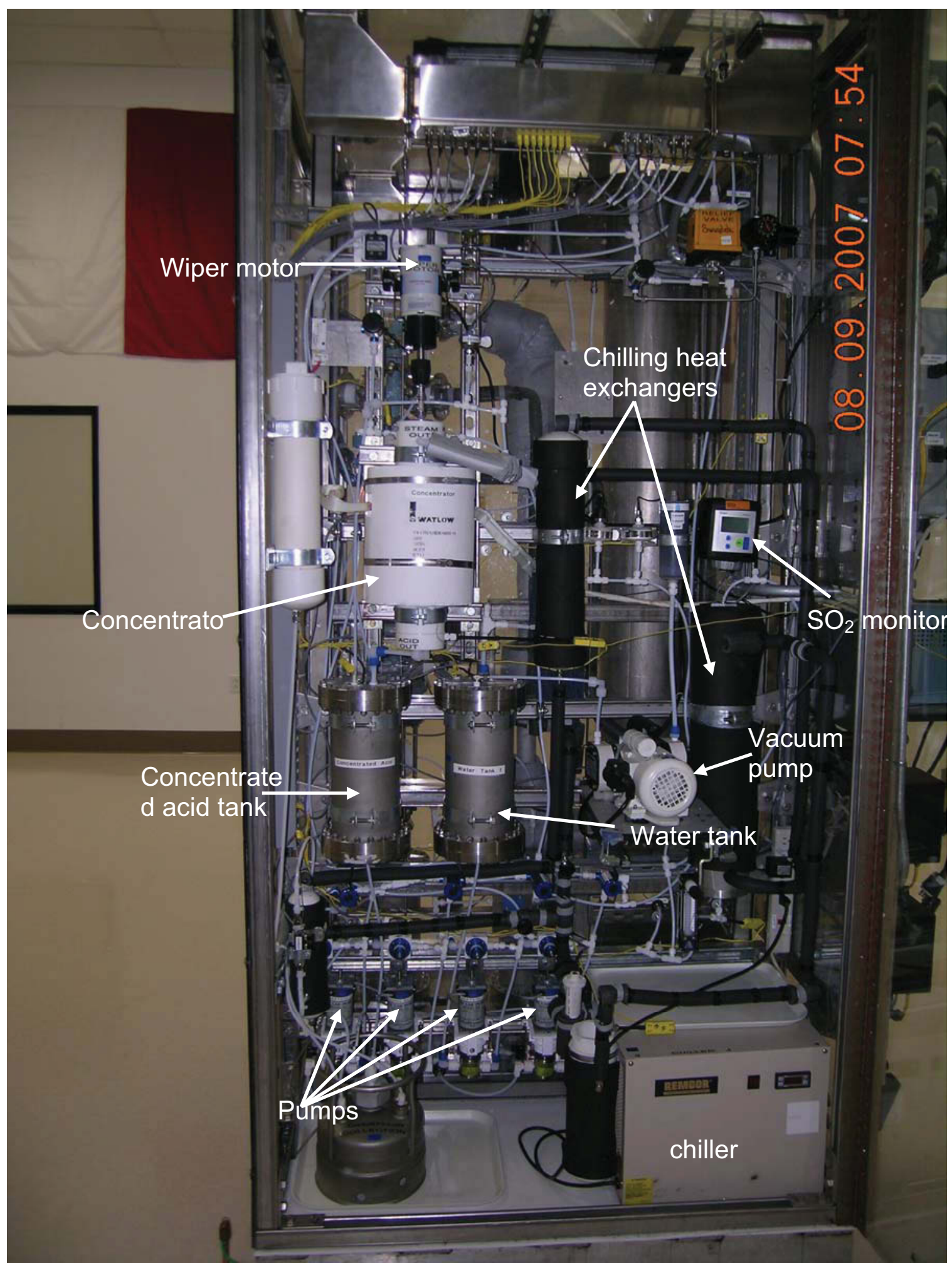

Figure 15 The liquid acid side of the acid decomposition skid assembled at GA. 


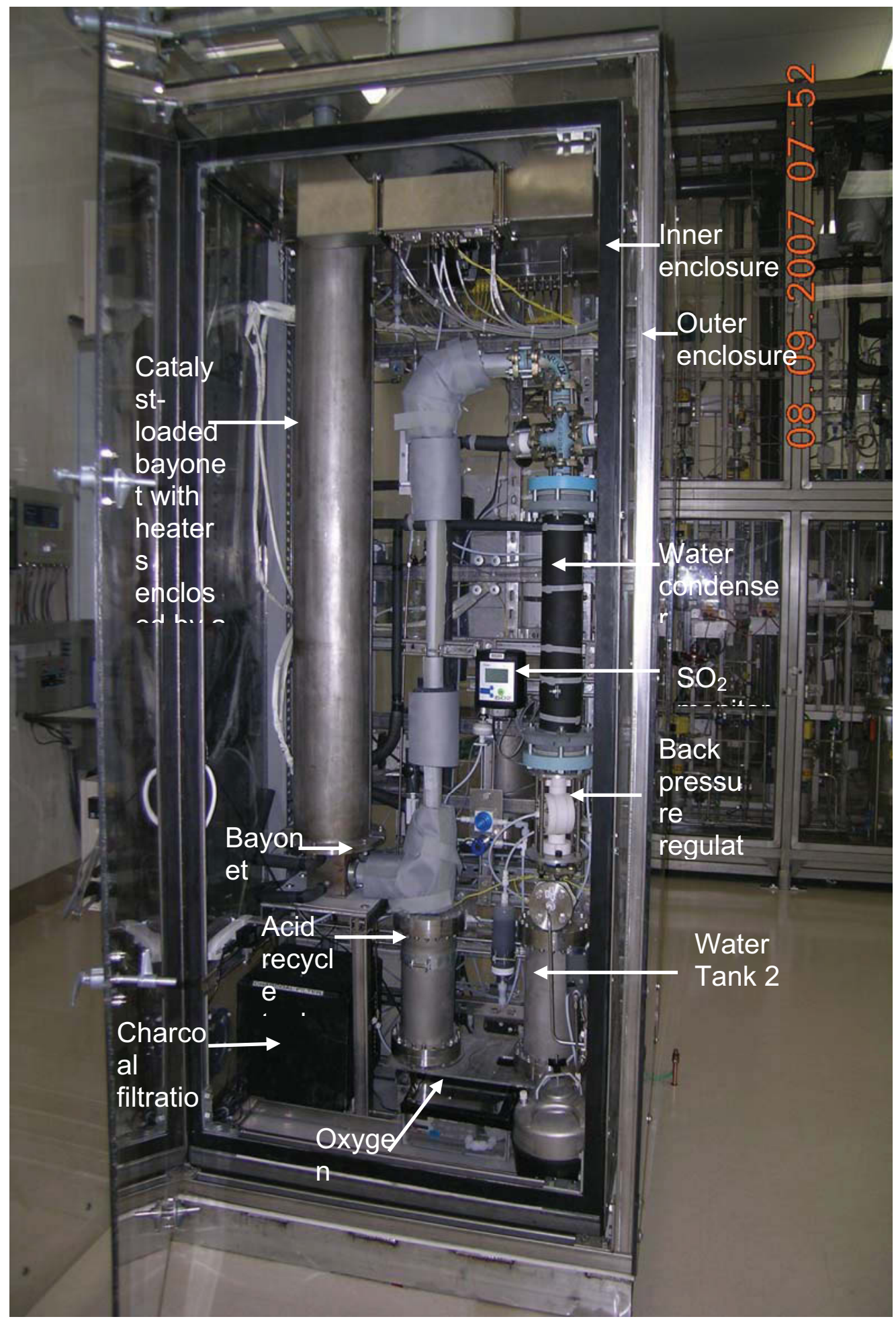

Figure 16 The $\mathrm{SO}_{2}$ side of the acid decomposition skid assembled at GA. 


\section{Acid Concentration}

Sulfuric acid enters the skid at approximately $20 \mathrm{~mol} \%$. Acid heating and acid concentration are accomplished in an electrically heated heat exchanger constructed of a SiC pipe with Teflon end caps. A schematic diagram of the concentrator in Figure 14 is given below in Figure 17.

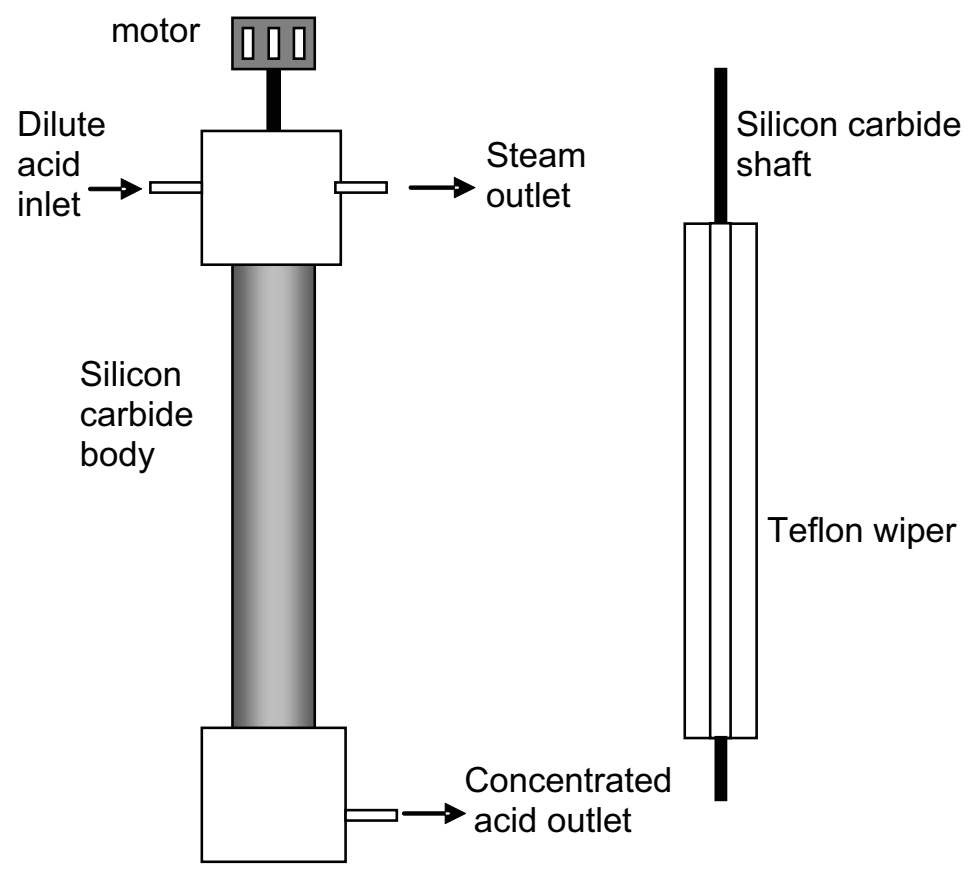

Figure17 Schematic of concentrator, excluding the surrounding electric heater.

The concentrator is a wiped-film type unit with a rotating inner Teflon wiper to maintain liquid contact with the heated walls. The concentrator is under vacuum which removes water vapor and concentrates the acid to approximately $40 \mathrm{~mol} \%$. Dilute acid enters the top of the concentrator and travels downward. The wiper, driven by a laboratory stirrer, increases contract of the liquid with the heated silicon carbide wall and increases the path length of the acid through the apparatus. For optimum efficiency, the concentration process is performed under sub-atmospheric pressure of approximately 1.0 psia. By lowering the pressure and therefore the boiling temperature of the acid, the energy required to heat the acid to its boiling point is decreased and input heat is mainly used for the heat of vaporization of the water from the dilute acid solution. Heat is supplied to the concentrator using a ceramic heater. Water is removed from the top of the apparatus as steam which is cooled to liquid water in a water-cooled condenser. The water is collected in a stainless steel pressure vessel labeled Water Tank 1 in Figures 16 and 16. A vacuum pump connected to the tank is used to maintain vacuum in the system including the acid concentrator pressure. 


\section{Bayonet Acid Decomposer}

The bayonet is shown schematically and as disassembled components in Figure 18. The operations of the bayonet have been described in previous reports (Moore et al., 2007; Gelbard et al. 2007). The basic operating parameters for the unit are the acid flow rate, the inlet acid temperature, and the maximum temperature. The bayonet is heated using electrical heaters controlled to a maximum temperature at the outside top portion of the bayonet. The products of acid decomposition are sulfur dioxide, oxygen and water vapor. These are separated from undecomposed acid in the lower section of the inner SiC tube.

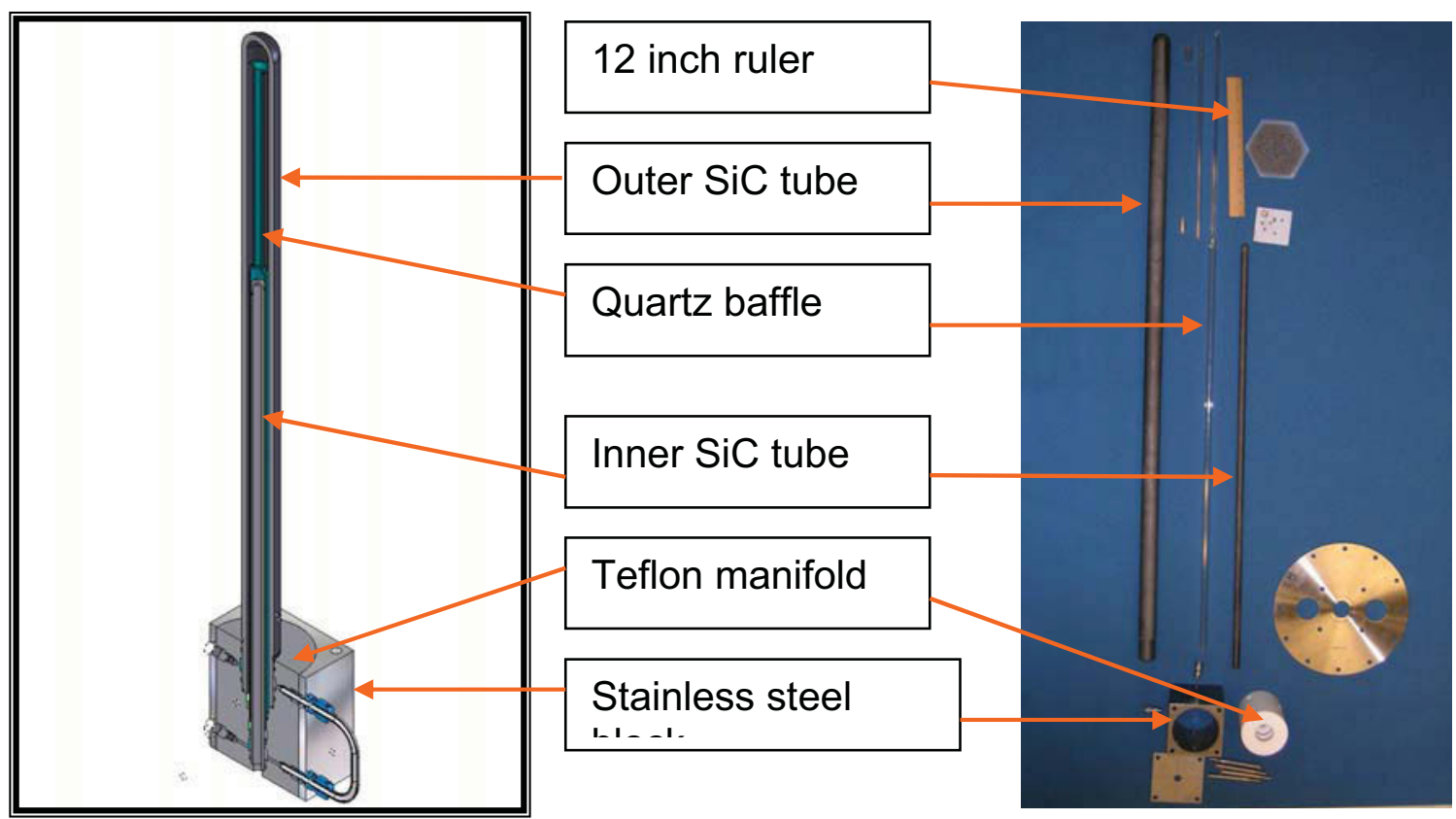

Figure 18 The SiC bayonet decomposer shown schematically on the left and the actual hardware on the right.

\section{HI Decomposition Skid Description (Section 3)}

The HI Decomposition section takes the heavy acid phase, which contains excess iodine and water in addition to the hydrogen iodide, from the Bunsen section. This skid separates the excess iodine and water from the feed by extractive distillation, utilizing phosphoric acid in a multi stage separation. The hydrogen iodide is decomposed at $450 \mathrm{deg}{ }^{\circ} \mathrm{C}$ to produce the hydrogen product. The installed skid is shown in Figure 19. 


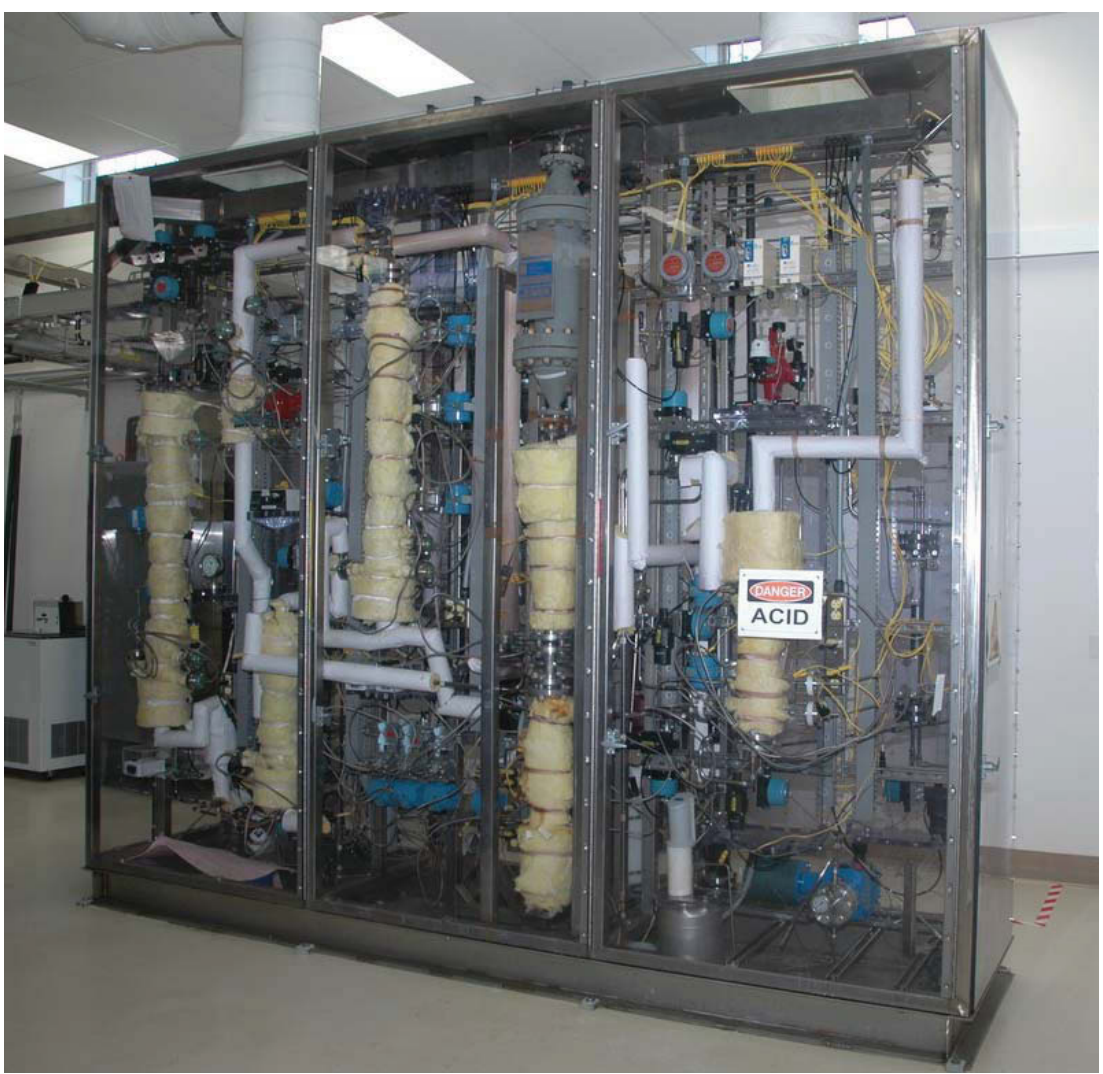

Figure 19 HI Decomposition Skid

The HI decomposition skid takes the HIx feed (2:8:10 molar ratios of $\mathrm{HI}$ :Water:lodine) from Section 1 and first removes the iodine in a liquid-liquid extraction process utilizing phosphoric acid. Next the $\mathrm{HI}$ is distilled from the remaining water-phosphoric acid solution and delivered to the reactor for decomposition to $\mathrm{I}_{2}$ and $\mathrm{H}_{2}$. As the reaction is limited to a $20 \%$ conversion thermodynamically, the unreacted $\mathrm{HI}$ must be separated and recycled in order to reach the desired $\mathrm{H}_{2}$ production rates. Initially both reactive and extractive distillation processes were evaluated. Based on experimental results, extractive distillation was selected as the HI distillation approach for the ILS experiment. The objectives of the extractive distillation demonstration were to construct a system capable of withstanding the highly corrosive chemicals, at a hydrogen production of $100 \mathrm{l} / \mathrm{hr}$ or greater, and demonstrate extraction of $\mathrm{HI}$ and $\mathrm{H}_{2} \mathrm{O}$ from HIx solution, and distillation of pure $\mathrm{HI}$.

\section{Task Overview - HI Decomposition Skid}

The progress to date includes the design, construction and operation of both reactive and extractive distillation experiments, and construction and initial testing of the extractive distillation ILS skid. Glass systems were constructed for 
both the reactive and extractive distillation experiments to enable a down selection between the two processes. The HI Decomposition Skid, as part of the DOE Integrated Lab Scale (ILS) experiment demonstrating closed-loop operation of the sulfur-iodine process, has been constructed and tested. The process system consists of 6 major components:

1. lodine extraction

2. HI distillation

3. HI decomposition

4. lodine and $\mathrm{HI}$ recycle

6. Phosphoric acid concentration

Each component has been tested at nominal temperature and pressure (120-450 $\operatorname{deg} \mathrm{C}$ and $11 \mathrm{bar}$ ). In stand-alone mode, premixed feed solutions were used to validate the operation and performance of the different components. The skid has been demonstrated at $30 \mathrm{l} / \mathrm{hr}$ with no recycle of the $\mathrm{HI}$, which is comparable to $300 \mathrm{l} / \mathrm{hr}$ with recycle. The recycle unit was not evaluated in this shakedown due to limited quantities of the premixed $\mathrm{HI}$ gas feed used for the reactor testing. A control system was also developed allowing for remote operation of the equipment. The control system has been designed to allow stand-alone operation as well as integration with the Supervisory Control System during integrated operation with the other process skids.

\section{Design Criteria of the HI Decomposition Section}

The HI Decomposition skid has been designed and constructed to meet the following criteria:

- Demonstrate the three component steps of the Sulfur-lodine process

- Demonstrate the operation of the integrated equipment

- Generate hydrogen at a rate of $100 \mathrm{l} / \mathrm{hr}$

- Construct equipment from engineering materials

- Operated at nominal temperature and pressures $\left(120\right.$ to $>450{ }^{\circ} \mathrm{C}$ and up to 20 bar)

- Construct experimental enclosure(s) to ensure safe operation and containment of any possible leaks or spills

- Design and implement a control system which allows for the remote operation of the equipment and for data logging of the process conditions

\section{Process Flowsheet}

The hydrogen iodide decomposition section for the ILS uses the extractive distillation method to produce hydrogen. The $\mathrm{HI}_{\mathrm{x}}$ feed is contacted with a concentrated phosphoric acid stream, which separates the water and hydrogen iodide from the iodine. This iodine stream is returned to Section 1 for use in the 
Bunsen reaction. The phosphoric acid/water/hydrogen iodide stream is then sent to a distillation column, where the phosphoric acid serves a second purpose by breaking the water/hydrogen iodide azeotrope that exists at approximately 15 mole $\%$ hydrogen iodide. This allows for a pure hydrogen iodide stream to be drawn from the top of the column. The reaction that occurs upon subsequent decomposition of hydrogen iodide is:

$$
2 \mathrm{HI} \rightarrow \mathrm{H}_{2}+\mathrm{I}_{2}
$$

The reaction takes place in a catalytic reactor at $450^{\circ} \mathrm{C}$. Activated carbon is used as the catalyst. The diluted phosphoric acid is concentrated and recycled back to the contactor with HIx.

The flowsheet for hydrogen iodide decomposition is shown in Figure 20. The flowsheet is scaled to one mole of hydrogen produced per hour. Equilibrium conversion of hydrogen iodide to hydrogen and iodine at $450^{\circ} \mathrm{C}$ is approximately $21 \%$. Thus, nearly $80 \%$ of the feed to the decomposition reactor must be recycled. Earlier flowsheets called for a membrane separator to recover the hydrogen product from unreacted hydrogen iodide, before recycling the hydrogen iodide back to the reactor. Currently no suitable membrane separator has been developed and therefore a membrane separator is not implemented in the ILS. Efforts for pursuing a membrane separator will continue, but in the interim a different design for separation of hydrogen iodide from hydrogen has been used in the ILS.

The gas-phase hydrogen iodide reactor loop operates at a pressure of 10-20 bar. The reactor product stream is cooled to $120^{\circ} \mathrm{C}$ to condense and separate the iodine for recycle back to Section 1 . The remaining hydrogen iodide/hydrogen stream is then sent to a vapor-liquid separator operating at $-40^{\circ} \mathrm{C}$, where the hydrogen iodide is condensed to a liquid. The vapor pressure of hydrogen iodide at this temperature is low enough that over $90 \%$ can be recovered in the liquid phase through a single pass in the separator. Once separated from hydrogen, the liquid hydrogen iodide is evaporated and the vapor is sent to the reactor. The residual hydrogen iodide remaining with the hydrogen product in the vapor phase is sent to a wash column. The vapor product of the wash column is the product hydrogen, and the water/hydrogen iodide liquid stream can be returned to Section 1 for use in the Bunsen reaction or sent back to the HI distillation column. 


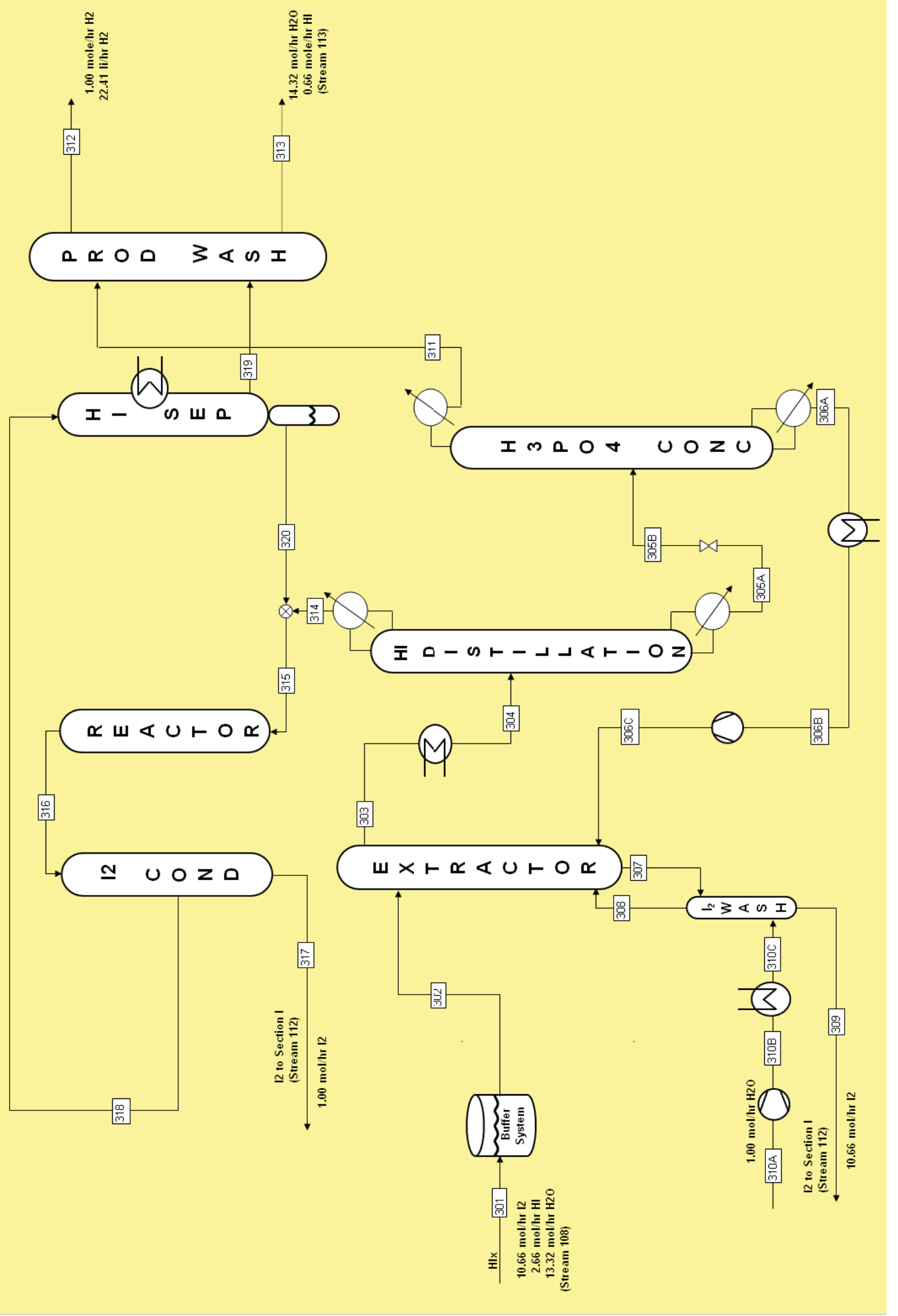

$\stackrel{2}{\circ}$ 


\section{Interface Skid Description and Controls}

A key issue regarding operation of the ILS is how the sections interact, both from materials exchange and from a supervisory control standpoint. Each section should be able operate independently during trials as well as operate together in an integrated mode. In addition, each section has waste management and ventilation treatment requirements.

One way to consolidate and simplify these issues is to collect all interface, storage and ventilation processing equipment onto a single, separate skid. Each section is provided with storage for both its inputs and outputs, and with treatment/storage/disposal capability as appropriate. A flowsheet illustrating the concept is shown in Figure 21.

The interface system between any two streams consists of two tanks, heated and pressurized as necessary, and pumps that are suitable for pumping the associated streams. Each group working on individual sections has recommended appropriate pumping technology. Dry and/or wet scrubbers are placed on the interface skid to process ventilation streams before release to the environment. The interface skid is a self-contained enclosure, with dedicated ventilation. In addition to storage tanks, the interface skid is equipped with a chemical scrubber. Sulfur dioxide or other chemicals not being used in integrated testing or chemicals that need to be vented during maintenance operations or other reasons are transferred to the scrubber.

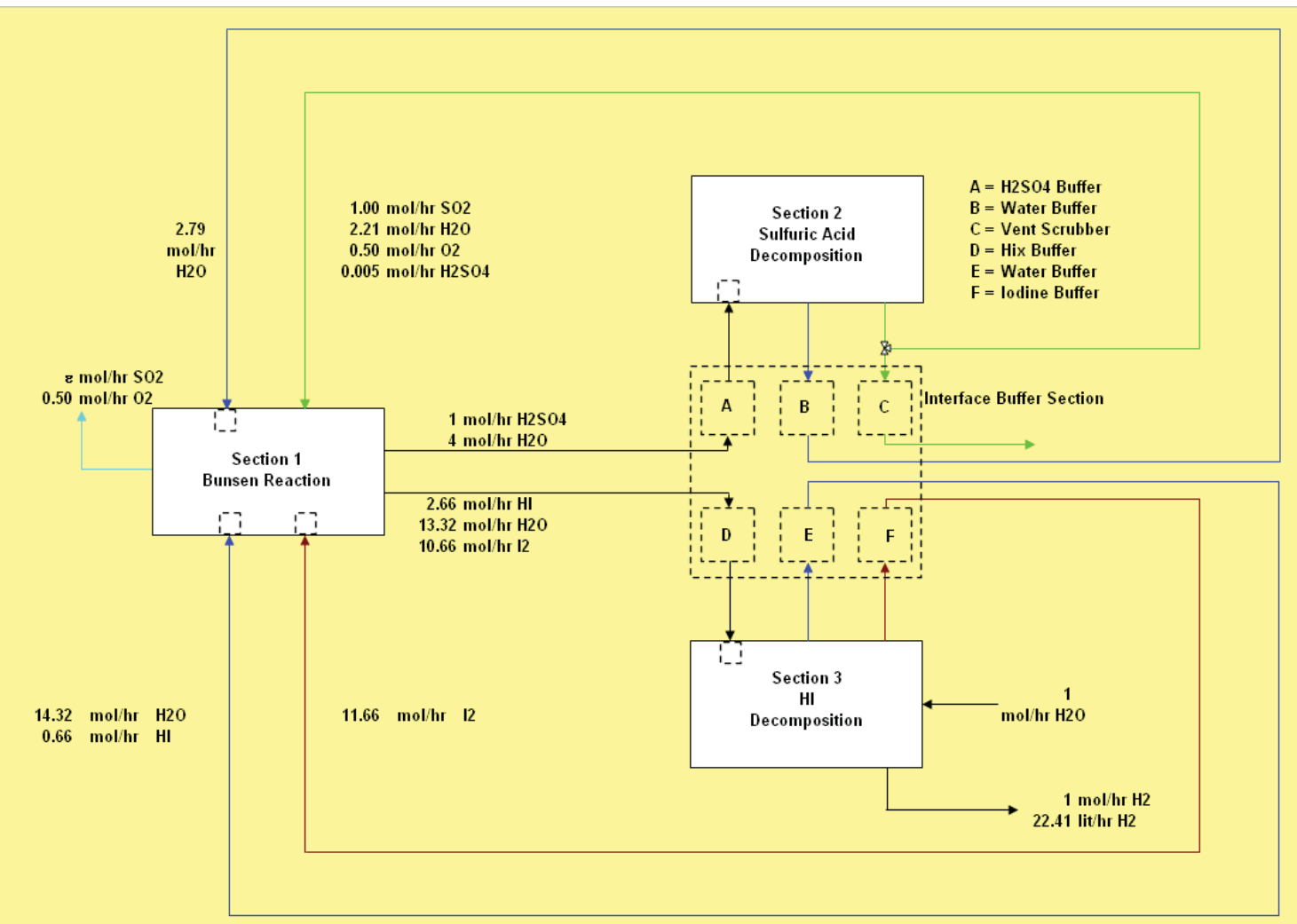

Figure 21 Interface skid flowsheet 
The installed interface skid is shown in Figure 22
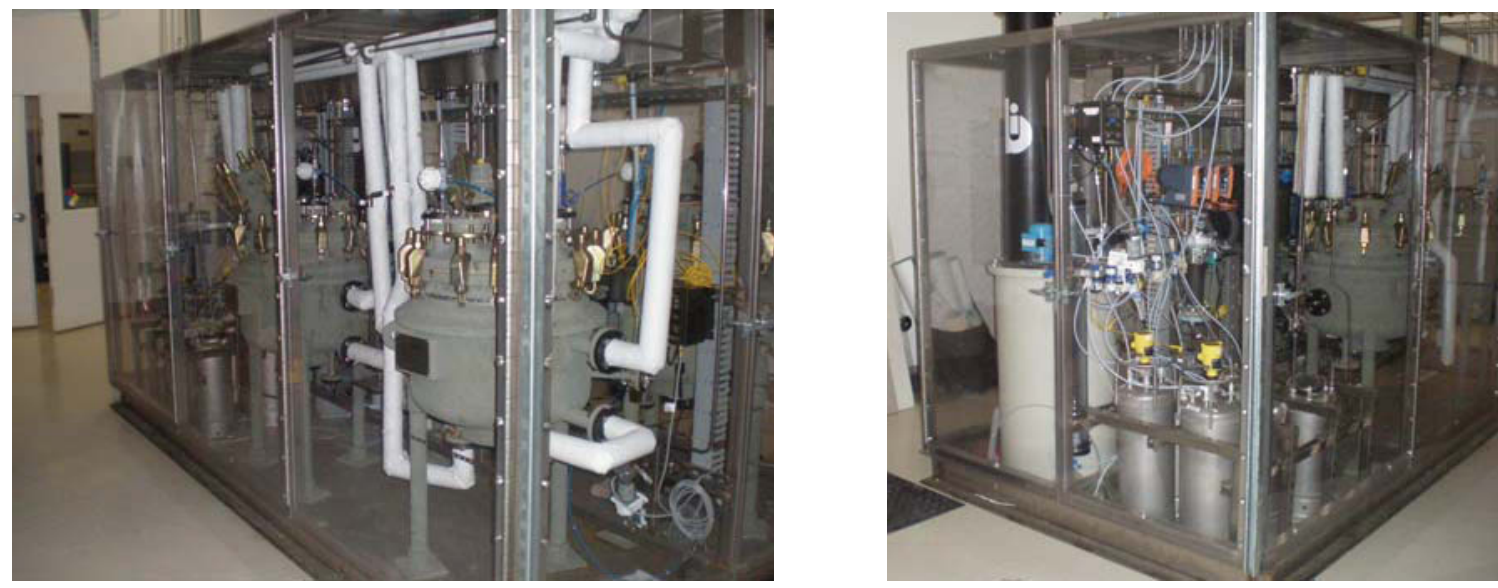

Figure 22 Interface Skid: $\mathrm{I}_{2} / \mathrm{HIx}$ tanks and Water $/ \mathrm{H}_{2} \mathrm{SO}_{4}$ tanks/Scrubber

\section{ILS Interfaces Between Section 1 and Section 2}

The primary interchange between Sections 1 and 2 is the delivery of dilute sulfuric acid from Section 1 to Section 2, and the return of a gas-phase $\mathrm{SO}_{2}$ stream from Section 2 to Section 1. A secondary liquid $\mathrm{H}_{2} \mathrm{O}$ stream will be sent to Section 1 from the condenser associated with the sulfuric acid condenser.

The delivery of dilute sulfuric acid to Section 2 is accomplished with a system of buffer tanks. Specifications are for the tanks to have a volume of 20 liters. The tanks are constructed from Teflon lined steel. The turnover time per tank is 8 hours at a hydrogen production rate of 200 liters per minute. The buffer tanks have level sensors to allow for the inventory of each tank to be measured over the entire volume capacity of the tank. By monitoring the inventory volume as a function of time, the flow rate in each tank can also be determined.

The $\mathrm{SO}_{2}$ vapor stream from Section 2 is either sent directly for use in Section 1 if the ILS is operating in an integrated mode, or it I is be processed through a chemical scrubber before venting. With the exception of small amounts on the CEA Bunsen process skid, $\mathrm{SO}_{2}$ is not stored. For stand-alone operation of Section $1, \mathrm{SO}_{2}$ from commercially available pressurized cylinders is used.

\section{ILS Interfaces Between Section 1 and Section 3}

The primary interchange between Sections 1 and 3 is the delivery of $\mathrm{HI}_{\mathrm{x}}$ solution from Section 1 to Section 3, and the return of a liquid-phase iodine stream from Section 3 to Section 1. A secondary liquid $\mathrm{H}_{2} \mathrm{O}$ stream is sent to Section 1 from the condenser associated with the phosphoric acid condenser. Consequently, the net water input to the ILS is located in Section 3. 
For the delivery of $\mathrm{HI}_{\mathrm{x}}$ to Section 3 , and for iodine delivery back to Section 1, a buffer tank system is used. Specifications are for the tanks to have 89-liter volumes and the ability to operate at pressures up to 2 bar, and at temperatures up to $130{ }^{\circ} \mathrm{C}$. The tanks are constructed of glass-lined steel. The turnover time per tank is 16 hours at a hydrogen production rate of 100 liters per minute. The buffer tanks and storage tank have level sensors to allow for the inventory of each tank to be measured over the entire volume capacity of the tank. By monitoring the inventory volume as a function of time, the flow rate in each tank is determined. Additionally, all $\mathrm{HI}_{x} /$ iodine plumbing/piping is heat-traced to $120^{\circ} \mathrm{C}$ to prevent iodine freezing.

\section{Summary Experimental Results}

Phase I of this project involved integration of the three process sections into a complete S-I cycle. The initial integrated operation was performed in April of 2008 and is documented in the SAND Report titled "Results of Phase 1 Testing of the Sulfur-lodine Integrated Laboratory-Scale Experiment". Phase II of the work includes completion of initial integrated shakedown operations, control verification tests (interface skid operations, production rate tests, shutdown tests), transient response tests (startup, shutdown, flow rate perturbations, mismatched flow rates), and cross talk tests (inter skid contamination and response) and process improvements or modifications as budgets permit. The results from phase I of the project along with additional standalone and integrated tests have identified issues for each process section that have been addressed in phase II work. These include redesign and replacement of major system components, corrosion control and modification of process monitoring. Several identified problems have led to very significant process modifications. However, for all three process sections, all major modifications have been completed.

The General Atomics hydrogen iodide section has undergone several modifications and has been successfully operated multiple times to produce hydrogen. The hydrogen iodide reactor has been replaced with a smaller unit to decrease the time for preheating the unit and reach equilibrium while operating. Using the smaller reactor, hydrogen has been produced at a rate of 10 to $75 \mathrm{~L} / \mathrm{hr}$. Problems with differential pressure cells used throughout the process for monitoring and control have been eliminated by replacing the units with higher quality units. Ta alloy corrosion problems were encountered due to hydrogen embrittlement of Ta vessels and piping. Most of these issues have been mitigated for the ILS with either modified operational conditions, or periodic replacement. Longer term solutions are being developed and will be tested in FY09.

The CEA has completed major modifications to the Bunsen section and the section is ready for additionally testing of the Bunsen reactor at this time. Completed modifications include: installation of a new Bunsen reactor equipped with Raching ring packing and differential pressure cells for enhanced process control and a redesign and modification of the system for transferring iodine from the chemical storage skid to the CEA skid. In 
addition to these modifications, additional integrated testing with the SNL acid decomposition section has been completed and the transfer of chemicals between the CEA section and the SNL sections is now considered routine. The CEA tested the new Bunsen reactor at the end of April 2008 as part of the final integrated operations with the SNL process section.

In the SNL acid decomposition section, system modifications include incorporation of an acid neutralization step to the process cooling water system to prevent corrosion of the circulating water chiller used in the process, an increased efficiency of the acid concentrator and the addition of a pressure control system to maintain a constant pressure in the acid decomposer. The acid decomposition process has been successfully operated multiple times over the past 18 months in the stand-alone and integrated modes. In the last operations of the process, the effect of temperature on acid decomposition was determined at a pressure of 1 bar. The results indicate the production of sulfur dioxide begins to decrease between 750 and $800^{\circ} \mathrm{C}$ with a decrease in gas production of $50 \%$ at $700^{\circ} \mathrm{C}$. No sulfur dioxide was detected at $650^{\circ} \mathrm{C}$.

The GA hydrogen iodide decomposition section and SNL acid decomposition section of the S-I process are ready for additional integrated testing. All modifications were completed and successful stand-alone tests have been performed with the new equipment as well as integrated operations with the Bunsen section

The results from the integrated tests in April, 2008 provided some initial results for the integrated system, but these results also indicated major equipment modifications were required for the CEA hydrogen production process and the GA hydrogen iodide decomposition process. Although in the CEA process hydrogen iodide was produced, it was determined that additional modifications were required and a modified Bunsen reactor has been installed. Once the operational parameters for the Bunsen reactor were identified integrated tests with all three process sections were continued. In addition to replacement of the reactor, a new iodine pumping system, using pressure to transfer iodine from the chemical storage skid to the Bunsen reactor, has been installed and successfully operated. The hydrogen decomposition reactor in the General Atomics hydrogen decomposition process has been replaced with a smaller unit and the process has been successfully operated multiple times to produce hydrogen at a rate of $75 \mathrm{~L} / \mathrm{min}$. The SNL acid decomposition process section has undergone several modifications to improve process efficiency and integrated operation. The most significant improvement is the installation of a backpressure regulator and buffer tank between the SNL section and the CEA section to prevent pressure fluctuations in the SNL acid decomposition reactor that can result in breakage of the unit. The SNL process has been successfully operated multiple times with sulfur dioxide produced at a rate of $100-300 \mathrm{~L} / \mathrm{hr}$.

\section{Uncertainties and Risk Reduction}


The sulfur-iodine cycle, coupled to a high temperature nuclear reactor, shows promise of economic hydrogen production in the future. Before nuclear hydrogen becomes commercial, the current uncertainties must be reduced. The technical uncertainties lie in several areas: chemistry, solution thermodynamics, chemical kinetics, and materials science. The economic uncertainties lie in the areas of capital and operating cost estimates, future costs of alternative clean (and dirty) hydrogen sources and the politics of global warming.

\section{TECHNICAL UNCERTAINTIES}

\section{Chemistry}

The chemistry of the Sulfur-lodine process is well understood and there are few potential side reactions. The side reactions, which could be problematic, are the formation of sulfur or hydrogen sulfide in Section 1 . Sulfur dioxide can be disproportionate to form either elemental sulfur or hydrogen sulfide along with sulfuric acid. These reactions are in competition with the much more rapid Bunsen reaction but are energetically more favorable. Any hydrogen sulfide that is formed will eventually be recycled back to the oxygen scrubbers in Section 1 where conditions are favorable to the formation of elemental sulfur from hydrogen sulfide and sulfur dioxide. Thus the ultimate questions concerning side reactions are how much sulfur, if any, will be formed, where will it go and what will happen to it? Elemental sulfur is molten at the exit temperatures of Section 1. Any sulfur accompanying the sulfuric acid to Section 2 would accumulate in the $\mathrm{H}_{2} \mathrm{SO}_{4}$ vaporizer where it would react with the $\mathrm{SO}_{3}$ forming $\mathrm{SO}_{2}$. More likely, any elemental sulfur formed will accumulate in the iodine recycle stream.

If sulfur accumulates in the iodine, the sulfur removal will need to be demonstrated. Sulfur and iodine should be easily separable by distillation as their boiling points of differ by over $250^{\circ} \mathrm{C}$. The sulfur would then be fed to the outlet of the sulfuric acid decomposer where the sulfur would be oxidized to $\mathrm{SO}_{2}$ by $\mathrm{O}_{2}$. Alternatively, the sulfur might be removed from the iodine by electrochemical oxidation. In either case, the maximum permissible concentration of sulfur in the iodine must be determined.

\section{Solution Thermodynamics}

The reactive distillation process for generating hydrogen appears to be viable but the current flowsheet is uncertain to the extent that the vapor-liquid equilibria of the system $\mathrm{HI} / \mathrm{I}_{2} / \mathrm{H}_{2} \mathrm{O}$ are based on models and not experimentally determined. There is also some uncertainty in the enthalpy of solution of this system. The missing data can either be determined by specific experiments or in integral form from operation of prototypical process steps.

The liquid-liquid equilibria for $\mathrm{HI} / \mathrm{I}_{2} / \mathrm{H}_{2} \mathrm{O} / \mathrm{H}_{2} \mathrm{SO}_{4}$ are also very limited. Additional data would allow extrapolation to operating conditions outside the current operating 
envelope. Alternatively, one could simply extend the operating range through operation of prototypical process equipment.

\section{Chemical Kinetics}

The chemical kinetics of $\mathrm{HI}$ decomposition under the conditions of the reactive distillation column are unknown. If the kinetics are too slow for economic operation, a noble metal catalyst may be needed. The kinetics need to be examined in the absence of catalyst and in the presence of supported catalysts in both gas and liquid phases and liquid phase solution catalysts.

\section{Material Science}

Significant headway has been made at determining applicable materials of construction for the sulfur-iodine process. Materials applicable to Sections 1 and 2 have been, for the most part, adequately researched. The one area of Section 2 that presents some concerns is that of boiling heat transfer. The only materials resistant to concentrated sulfuric acid at the gas-liquid interface tend to be brittle materials such as siliconized cast iron and silicon carbide. Small heat exchangers have been made from such materials but such exchangers must be developed in the required sizes.

The containment materials for Section 3 will be similar to those in Section 1. The higher temperatures of Section 3 will be accommodated by the use of corrosion resistant insulating materials inside the chemical containment boundary. The heat transfer materials used in Section 1 may also be usable at the higher temperatures encountered in Section 3 but this needs to be verified.

\section{ECONOMIC UNCERTAINTIES}

The economic uncertainties are twofold: the projection of future hydrogen costs from alternative sources and the uncertainties in the capital cost of the nuclear hydrogen plant. We have no control over the future cost of hydrogen from alternative sources. The future cost of hydrogen from fossil sources will certainly increase. The increase may be dramatic if carbon sequestration is mandated or a carbon tax is imposed.

The uncertainties in the capital cost of the reactor and chemical plant are manageable. The cost estimate for the GT-MHR was performed very recently, with the aid of an A\&E firm. The cost of the PH-MHR was derived from the GT-MHR cost by eliminating systems and should be equally firm. The cost presented for the H2-MHR was extrapolated from the PH-MHR cost and should be updated during the current DOE effort at defining a Very High Temperature Reactor (VHTR) as part of their Generation IV effort. The uncertainties in the cost of the chemical plant will be reduced as the chemical uncertainties are reduced and a pilot plant is designed. 


\section{RECOMMENDATIONS FOR RISK REDUCTION}

There are two possible approaches to obtaining the data necessary to implement largescale production of hydrogen using the sulfur-iodine process and thus overcoming the technical uncertainties indicated. The first is a science based approach utilizing a systematic and methodical examination of each area of uncertainty before proceeding further. The second is an engineering approach that builds on previous work in the area to provide specific targeted technology demonstrations. The science-based approach has the least risk but will delay the potential benefits to the nation of reduced pollution and increased reliability of the national energy supply. The engineering approach will provide clean hydrogen from nuclear energy in the shortest time frame and at the lowest overall development cost, but has some risks.

We believe that a combination of the two approaches is optimal. We recommend that the engineering development be carried out in five phases: (1) demonstration of the complete process chemistry in an integrated laboratory scale flow loop, (2) design, fabrication, and operation of an engineering demonstration loop, (3) design, fabrication, and operation of a small nuclear hydrogen production demonstration plant, (4) design, fabrication, and operation of the first commercial nuclear hydrogen demonstration plant based on a single reactor module, and (5) design, fabrication, and operation of the first full scale nuclear hydrogen production demonstration plant powered by multiple reactor modules.

The first three phases will require government participation but, assuming the demonstration plant is a success, the last two phases should be financed by industry. Laboratory studies, especially solution thermodynamics and material science investigations, should be carried out simultaneously with the engineering development, particularly during two demonstration phases. The material sciences investigations, in particular, can be "piggy backed" on to the operation of the demonstration loops at a minimal cost. During each phase engineering models of the process should be updated based on the latest scientific information and on operational data from the previous phase of scaleup. Table 4 gives the recommended scaleup steps and the degree to which process conditions and equipment construction would be typical of the final fullscale production plant. The efficiency will increase as the scale is increased due to the increased thermal integration possible with larger plants, the decrease in heat losses from larger equipment, and the concurrent development of higher temperature nuclear reactors. 
Table 4 Recommended Scaleup steps for SI process

\begin{tabular}{|l|l|l|l|l|r|}
\hline \multicolumn{2}{|l|}{ Recommended Scaleup Steps } & \multicolumn{1}{l|}{ Hydrogen } \\
\hline Materials & Heat Source & Integration & Efficiency & (kg/day) \\
\hline $\begin{array}{l}\text { Laboratory } \\
\text { demonstration } \\
\text { loop }\end{array}$ & $\begin{array}{l}\text { Primarily glass/quarts } \\
\text { with selected } \\
\text { prototypical } \\
\text { components }\end{array}$ & Electrical & None & Nil \\
\hline $\begin{array}{l}\text { Engineering } \\
\text { demonstration } \\
\text { loop }\end{array}$ & Prototypical & $\begin{array}{l}0.5 \mathrm{MW} \\
\text { Electrical }\end{array}$ & Minimal & $20 \%$ & 60 \\
\hline Pilot plant & Prototypical & $\begin{array}{l}5 \mathrm{MW} \\
\text { Electrical }\end{array}$ & Moderate & $30 \%$ & 900 \\
\hline $\begin{array}{l}\text { Demonstration } \\
\text { plant }\end{array}$ & Prototypical & $\begin{array}{l}50 \mathrm{MWt} \\
\text { Nuclear }\end{array}$ & Full & $40 \%$ & 12000 \\
\hline $\begin{array}{l}\text { Commercial } \\
\text { demonstration }\end{array}$ & Commercial & $\begin{array}{l}600 \mathrm{MWt} \\
\text { Nuclear }\end{array}$ & Full & $42 \%$ & 150000 \\
\hline $\begin{array}{l}\text { Commercial } \\
\text { production }\end{array}$ & Commercial & $\begin{array}{l}2400 \mathrm{MW} \mathrm{t} \\
\text { Nuclear }\end{array}$ & Full & $52 \%$ & 760000 \\
\hline
\end{tabular}




\section{References}

Baxter, 2005 Baxter, A., et al., "MHR Fuel Cycle Options for the Future Sustainability of Nuclear Power," Proceedings of Global 2005, October 9-13, 2005, Tsukuba, Japan, Paper 314.

Borchardt, 1982 Borchardt, G., et al., "Experiment FRJ2-P24 Bestrahlungsbericht," Interner Bericht KFA-ZBB-IB-19/82, Kernforschungsanlage Jülich $\mathrm{GmbH}$, Jülich, Federal Republic of Germany, August 1982.

Bullock, $1983 \quad$ Bullock, R.E. and J.L. Kaae, "Performance of Coated UO2 Particles Gettered with ZrC," J. Nuc. Mat., 115, 69 (1983).

Bullock, $1984 \quad$ Bullock, R.E., "Fission-Product Release During Post irradiation Annealing of Several Types of Coated Fuel Particles," J. Nuc. Mat, 125, 304 (1984).

Brown, 2003 Brown, L.C., et al., High Efficiency Generation of Hydrogen Fuels Using Nuclear Power, GA-A24285, Rev. 1, General Atomics, San Diego, CA, December 2003.

Carlson, 1986 Carlson, K., P. A. Roth, and V. H. Ransom, ATHENA Code Manual Volume I: Code Structure, System Models, and Solution Methods, EGG $\neg$ RTH-7397, Idaho National Engineering Laboratory, Idaho Falls, ID, 1986.

DOE, 2005 Nuclear Hydrogen Initiative Ten Year Program Plan, Department of Energy, Office of Advanced Nuclear Research, March 2005.

http://neri.inel.gov/program_plans/pdfs/nhi_plan.pdf

EPRI, 2003 High-Temperature Gas-Cooled Reactors for the Production of Hydrogen: An Assessment in Support of the Hydrogen Economy," EPRI Report 1007802, Electric Power Research Institute, Palo Alto, CA, April 2003.

Hanson, 2004 Hanson, D. and J. Saurwein, Development Plan for Advanced High Temperature Coated-Particle Fuels, PC-000513, Rev. 0, General Atomics, San Diego, CA, 2004.

IAEA, 1997 Fuel Performance and Fission Product Behavior in Gas Cooled Reactors, IAEA-TECDOC-978, International Atomic Energy Agency, Vienna, Austria, November 1997.

Inaba, 2005 Inaba, Y., et al., "Study on Control Characteristics for HTTR Hydrogen Production System with Mock-up Test Facility. System Controllability Test for Fluctuation of Chemical Reaction," Nuclear Engineering and Design," 235, pp, 111-121, 2005.

lyoku, 2005 lyoku, T., et al., "HTTR Test Program Towards Coupling with the SI Process," Third Information Exchange Meeting on the Nuclear Production of Hydrogen and Second HTTR 
Workshop on Hydrogen Production Technologies, Japan Atomic Energy Agency, Oarai, Japan, October 5-7, 2005, OECD Nuclear Energy Agency, Paris, France.

Kubo, 2005 LaBar, $2003 \quad$ Kubo, S., et al., "A Bench-Scale Hydrogen Production Test by the Thermochemical Water-Splitting lodine-Sulfur Process," Proceedings of Global 2005, October 9-13, 2005, Tsukuba, Japan, Paper 474. LaBar, M., et al., "The Gas Turbine Modular Helium Reactor," Nuclear News, Vol. 46, No. 11, p. 28 (2003).

Maruyama, $1994 \quad$ Maruyama, S. et al., "Evaluation of Core Thermal and Hydraulic Characteristics of HTTR," Nucl. Eng. Des., Vol. 152, pp. 183-196, 1994.

Minato, 1995 MINATO, K., et al., "Review of Experimental Studies of Zirconium Carbide Coated Fuel Particles for High Temperature Gas-Cooled Reactors," JAERI-Review-95-004, Japan Atomic Energy Research Institute, Oarai, Japan (1995).

Myers, 1987 Myers, B., Fuel Design Data Manual, MAN-910866, Issue F, General Atomics, San Diego, CA, August 1987.

Nishihara, $2005 \quad$ Nishihara, T., et al., "Analytical Study on Hydrogen Dispersion in the HTGR Hydrogen Production System," Proceedings of Global 2005, Tsukuba, Japan, October 913, 2005, Paper No. 284.

Norman, $1982 \quad$ Norman, J., et al., Thermochemical Water-Splitting Cycle, Bench-Scale Investigations and Process Engineering, Final Report for the Period February 1977 through December 31, 1981, GA-A16713, General Atomics, San Diego, CA, 1982.

Ohashi, 2005 Ohashi, H., et al., "Current Status of Research and Development on System Integration Technology for Connection between HTGR and Hydrogen Production System at JAEA," Third Information Exchange Meeting on the Nuclear Production of Hydrogen and Second HTTR Workshop on Hydrogen Production Technologies, Japan Atomic Energy Agency, Oarai, Japan, October 5-7, 2005, OECD Nuclear Energy Agency, Paris, France.

Petti, 2005 Petti, D., et al., Technical Program Plan for the Advanced Gas Reactor Fuel Development and Qualification Program, INL/EXT-05-00465, Rev. 1, Idaho National Laboratory, Idaho Falls, ID, August 2005.

Richards, 2004 Richards, M., et al., "Thermal Hydraulic Design of a Modular Helium Reactor Core Operating at $1000^{\circ} \mathrm{C}$ Coolant Outlet Temperature," Proceedings of the 6th International Conference on Nuclear Thermal Hydraulics, Operations and Safety (NUTHOS-6), October 4-8, 2004, Nara, Japan, Atomic Energy Society of Japan, Tokyo, Japan, 2004.

Schultz, $2004 \quad$ Schultz, R., et al., Next Generation Nuclear Plant - Design Methods Development and Validation Research and Development Program Plan, INEEL/EXT-04-02293, Idaho National Engineering and Environmental Laboratory, Idaho Falls, ID, September 2004.

Shenoy, 1996 Shenoy, A.S., GT-MHR Conceptual Design Description Report, RGEᄀ910720, Rev. 1, General Atomics, San Diego, CA, July 1996. 
Smith, 2005 Smith, C., et al., An Engineering Analysis for Separation Requirements of a Hydrogen Production Plant and High-Temperature Nuclear Reactor, INL/EXT-0500317, Rev. 0, Idaho National Laboratory, Idaho Falls, ID, USA, March 2005.

Summers, 2004 Summers, W., et al., Centralized Hydrogen Production from Nuclear Power: Infrastructure Analysis and Test-Case Design Study, Interim Project Report, Phase A Infrastructure Analysis, NERI Project 02-160, WSRC-TR-2004-00318, Rev. 0, Westinghouse Savannah River Company, Savannah River National Laboratory, Aiken, SC, July 2004.

Summers, 2006 Summers, W., et al., Centralized Hydrogen Production from Nuclear Power: Infrastructure Analysis and Test-Case Design Study, Final Project Report, Phase B Test-Case Preconceptual Design, NERI Project 02-160, WSRC-MS2005-00693, Rev. 0, Westinghouse Savannah River Company, Savannah River National Laboratory, Aiken, SC, February 2006.

Terada, 2005 Terada, A., et al., "Development of Hydrogen Production Technology by Thermo-Chemical Water Splitting Process - Pilot Test Plan," Proceedings of Global 2005, October 9-13, 2005, Tsukuba, Japan, Paper 427. 